\title{
Velhas tradições e gente nova no pedaço: perspectivas longevas de arquitetura funerária na paisagem do litoral sul catarinense
}

\author{
Paulo DeBlasis* \\ Deisi S. Farias ** \\ Andreas Kneip **
}

DeBLASIS,P., FARIAS, D. S., KNEIP, A. Velhas tradições e gente nova no pedaço: perspectivas longevas de arquitetura funerária na paisagem do litoral sul catarinense. R. Museu Arq. Etn., 24: 109-136, 2014.

Resumo: Inserido em um contexto que o coloca, tanto geográfica quanto historicamente, entre as culturas sambaquieira e Je do Sul, o sítio funerário Galheta IV, situado no litoral sul catarinense e datado em torno de 1000 AP, traz características peculiares que o situam na confluência do contato, aparentemente fluído, entre estas duas culturas. Este artigo discute estas características mostrando que, se de um lado o sítio traz elementos tipicamente Je em sua constituição, por outro se insere harmonicamente em uma paisagem fortemente marcada pela milenar presença sambaquieira.

Palavras-chave: Je do Sul, sambaquis, litoral sul catarinense, arqueologia costeira

\section{Introdução}

s estudos acerca da expansão Je no
planalto meridional brasileiro têm avançado bastante nos últimos anos, mapeando aos poucos as características culturais, sociais e territoriais desses grupos em época anterior aos registros escritos. Tanto nas terras altas, como também na encosta da serra que emoldura a

(*) Museu de Arqueologia e Etnologia, Universidade de São Paulo <deblasis@usp.br>

$\left.{ }^{(* *}\right)$ UNISUL/GRUPEP, campus Tubarão.<deisiarqueologia@ gmail.com>

${ }^{(* * *)}$ Universidade Federal do Tocantins. <andreas@mail. uft.edu.br> fachada atlântica do continente, os grupos portadores de línguas Je do Sul alcançaram grande dispersão territorial a partir de pouco mais de mil anos atrás, marcando as paisagens amplas e abertas do altiplano com grandes conjuntos de arquitetura residencial, ritual e funerária. Nesta mesma época seus sítios se multiplicam ao longo da costa, território há muito dominado pela sociedade sambaquieira, ela própria detentora de longeva tradição de arquitetura funerária, construída de forma bastante ritualizada e adquirindo, frequentemente, proporções monumentais. Pouco se sabe acerca do contato entre estes grupos, mas é certo que aos recém-chegados à costa não passou despercebida a imponên- 
Velhas tradições e gente nova no pedaço: perspectivas longevas de arquitetura funerária na paisagem do litoral sul catarinense R. Museu Arq. Etn., 24: 109-136, 2014.

cia com que os sambaquieiros imprimiram, na paisagem aplainada das lagoas e lagamares, sua história, a de seus ancestrais.

Este artigo apresenta um estudo de Galheta IV, um sítio cerimonial assentado sobre um promontório cristalino no litoral sul catarinense, em meio a um cenário litorâneo espetacular, marcado pela presença de dezenas de sambaquis. Sendo ele mesmo uma construção monticular, este sítio exibe, no entanto, características formativas bastante distintas da constituição típica dos concheiros da região. Devido à cerâmica nele encontrada, foi associado à tradição Taquara, interpretação corroborada pela cronologia tardia, em torno de $1000 \mathrm{AP}^{1}$, o que o situa em época bem posterior ao período de maior expansão da cultura sambaquieira, mas plenamente contem-

(1)Todas as referências cronológicas deste texto, mesmo as discursivas ou genéricas, são em anos radiocarbônicos, calibrados antes do Presente (AP). porâneo da grande expansão daquela tradição (p.e. Beber 2005, Iriarte et al 2012, entre outros). A ocorrência de práticas funerárias diversas em um mesmo contexto deposicional, assim como a inserção deste novo sítio em uma paisagem dominada há milênios pelas altaneiras estruturas sambaquieiras, levou de imediato a pensar nas relações entre os sambaquieiros, habitantes tradicionais da região, e grupos de língua Je, portadores de cerâmica Taquara e modos de vida diferentes, que ao longo do segundo milênio vão se achegando à costa sul catarinense.

\section{O complexo arqueológico da Ponta da Galheta}

Em meio ao litoral sul catarinense, entre Laguna e o cabo de Santa Marta, encontra-se a Ponta da Galheta (ou Cabo de Santa Marta Pequeno), promontório (pontão) formado por um afloramento cristalino avançado entre praias (antiga ilha, hoje incorporada ao continente), isolado do ambiente lagunar situado

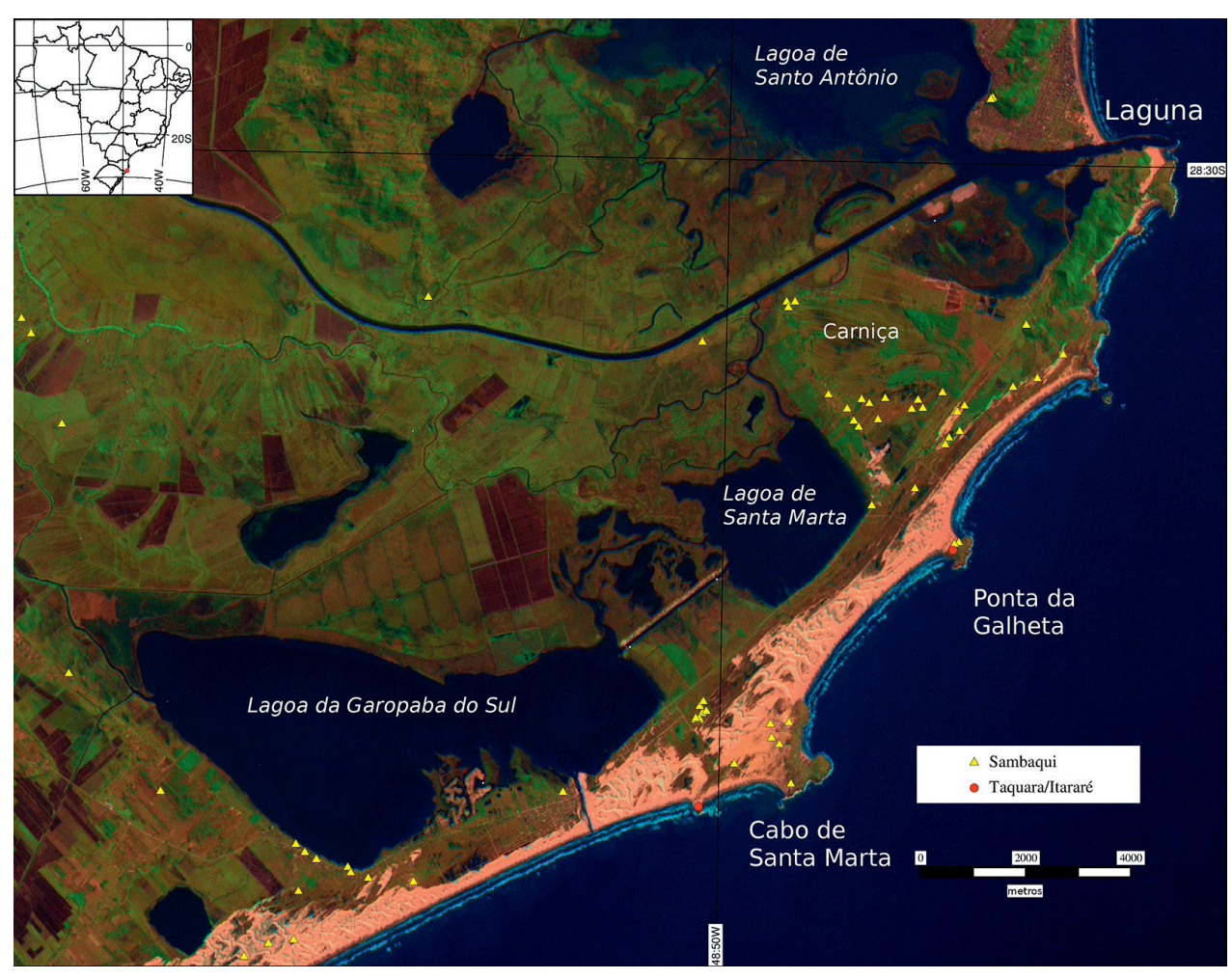

Fig. 1. Os sítios da Ponta da Galheta e seu entorno (A. Kneip). 
mais para o interior por um extenso e ativo campo de dunas. Com cerca de cinquenta metros acima do nível do mar, o pontão oferece não apenas amplo domínio de uma grande extensão oceânica (de nordeste a sul), mas também uma ótima visão da região da planície quaternária costeira com suas belíssimas lagoas, cercadas ao norte e a oeste pelas serras que antecedem a cuesta da Serra Geral (fig. 1). Dali também se pode ver diversos sambaquis, localizados no topo e no entorno do cabo (outra paleoilha) de Santa Marta, ao sul (fig. 3a) e, a norte/noroeste, não muito distante, o agrupamento de sambaquis grandes e pequenos da Lagoa dos Bichos e da Carniça, entre outros. Ao fundo, ao norte, vislumbra-se o que restou do famoso sambaqui da Cabeçuda.

Sobre este afloramento encontram-se três sítios arqueológicos monticulares, formando um conjunto de grande impacto visual (fig. 2). Assentados sobre o flanco interno do promontório (voltados para a laguna, e não para o mar aberto) encontram-se dois sambaquis, bem diferentes entre si. Galheta I destaca-se por suas dimensões monumentais, e seus mais de 250 metros de comprimento e cerca de 20 metros de altura fazem dele o ponto culminante do afloramento, elevando-se mesmo acima dos topos rochosos que o ladeiam, sendo amplamente visível desde toda a área praiana e lagunar situada para a face norte, inclusive a partir de vários outros sambaquis. A seus pés (cerca de 80 metros) encontra-se outro sambaqui, Galheta II, pequeno e de formato cônico, com aproximadamente três metros de altura e cerca de 20 metros de diâmetro, assentado sobre dunas antigas, consolidadas, no sopé do morro (fig. 3b). Datações provenientes do topo destes sambaquis revelam sua maior antiguidade, com mais de 3000 anos AP (fig. 4).

A outra formação monticular, bem mais recente (em torno de $1000 \mathrm{AP}$ ), encontra-se sobre a porção interna, um pouco mais ao sul, do afloramento. Galheta IV constitui-se em um pequeno mound de formato elipsoide, predominantemente arenoso, com cerca de dois metros de altura e vinte e cinco metros em seu eixo mais alongado, bastante discreto, mas

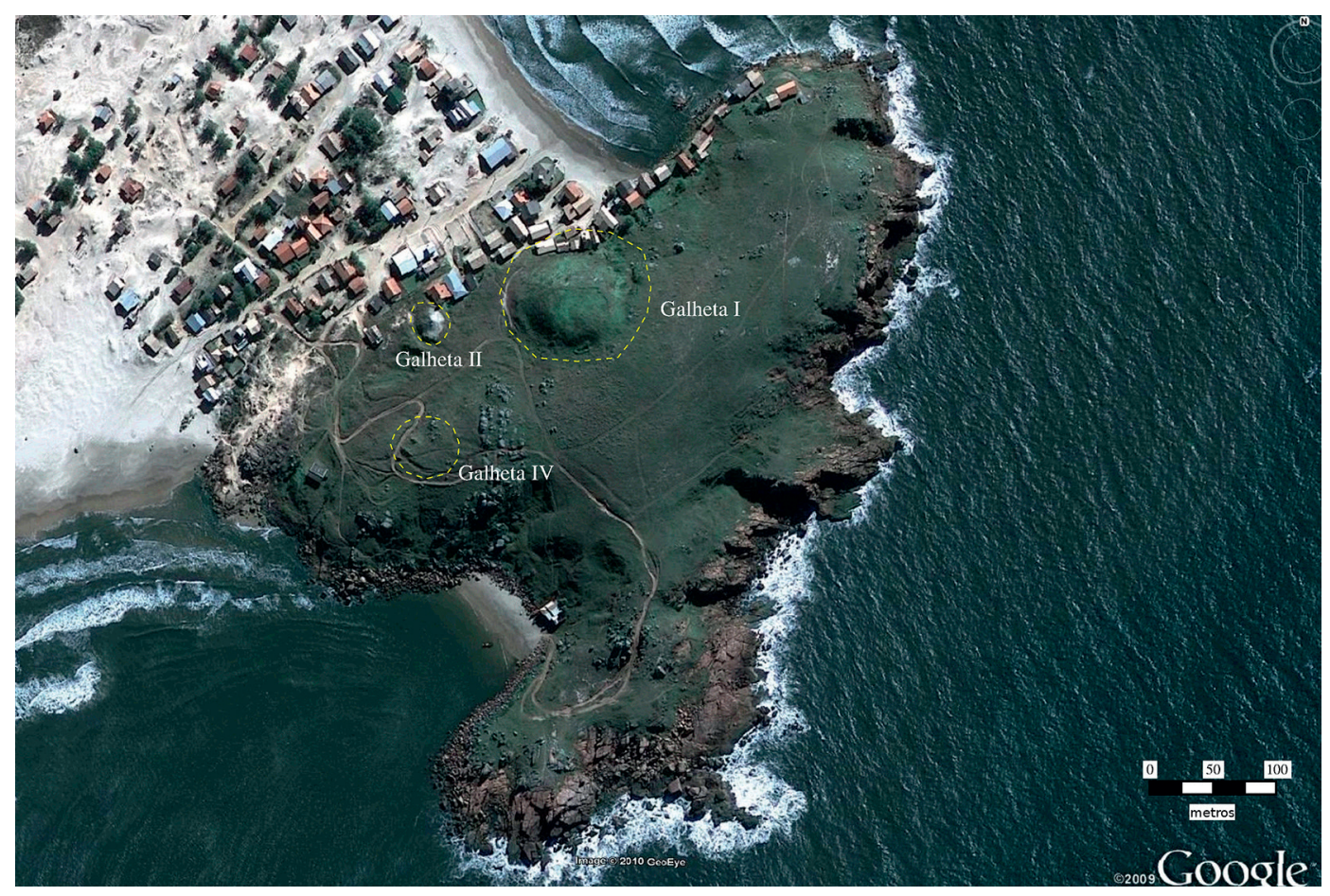

Fig. 2. O complexo arqueológico da Galheta (A. Kneip). 


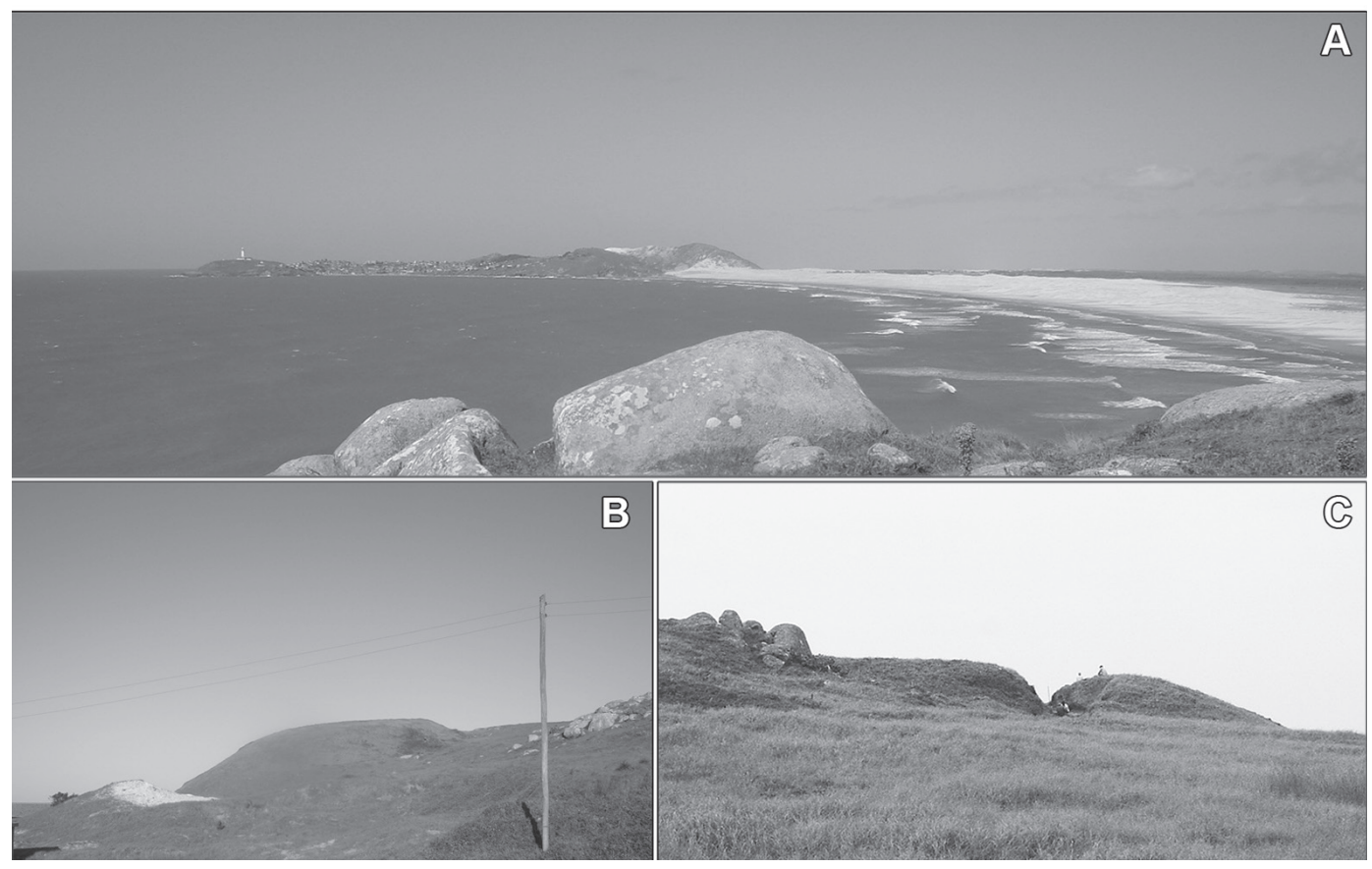

Fig. 3. a) Vista do cabo de Santa Marta, a sudoeste, a partir da Galheta. No topo do morro, esbranquiçado, podese ver o sambaqui Santa Marta III. b) Os sambaquis da Galheta vistos desde abaixo de Galheta IV, destacando a monumentalidade do conjunto paisagístico. Galheta I é o grande sambaqui no centro da foto, Galheta II o pequeno montículo esbranquiçado a seus pés no lado esquerdo. c) Galheta IV visto da base do morro, a nordeste (nas proximidades de Galheta II), observando-se sua silhueta monticular (fotos P. DeBlasis).

ainda perceptível a partir da base do morro (fig. 3c). Em sua matriz arenosa as conchas são bastante rarefeitas, em meio a grande quantidade de vestígios faunísticos, líticos e alguma cerâmica Taquara, dispersos por toda a área do sítio. Encontram-se ali também diversos sepultamentos, acompanhados de feições concrecionadas muito ricas em material faunístico e carvões.

As construções monticulares não constituem os únicos vestígios arqueológicos sobre a "ilha". As escavações em Galheta IV foram complementadas por uma malha sistemática de testes de subsuperfície disposta por toda a área do pontão, de modo a mapear as características de uso e ocupação do entorno deste sítio e dos sambaquis assentados sobre o costão rochoso da Galheta. Estas prospecções sistemáticas de varredura (full-coverage), desenvolvidas no âmbito do projeto Sambaquis e
Paisagem (Farias e DeBlasis 2007, Assunção 2010) $)^{2}$, revelaram a presença de considerável quantidade de vestígios líticos (pequena debitagem e fragmentos rochosos queimados, em sua maioria) e cerâmicos bastante dispersos por toda a área do pontão, e ainda duas pequenas concentrações superficiais de vestígios líticos e cerâmicos aparentando acampamentos ou áreas de uso específico, que não foram escavadas. Esta variedade de vestígios e materiais indica ampla circulação por toda a área do pontão e sugere a presença de um palimpsesto de múltiplos momentos de ocupação ao

2 Este projeto interdisciplinar vem sendo desenvolvido desde 1995 no litoral sul catarinense, tendo por objetivo estudar estes sítios litorâneos de uma perspectiva histórica regional, com foco nos processos formativos vis-a-vis a evolução dinâmica do Quaternário costeiro (DeBlasis e Gaspar 2009, Giannini et al 2010). 
longo de vários milênios, dos sambaquieiros à presença Taquara mais tardia. Cabe observar que, até hoje, a área é um excelente ponto de pesca, havendo um pequeno porto numa prainha do pontão voltada para sul (fig. 2). Além do pontão, alguns outros sítios com cerâmica Taquara da região são contemporâneos a Galheta IV (fig. 1 e 4 , tabela 1), que se integra assim a um contexto de ocupação mais amplo, discutido ao final deste artigo.

Tendo em vista que os vestígios arqueológicos presentes na área do sítio Galheta IV encontram-se dispersos de maneira aparentemente homogênea, fluida, no pacote arenoso escuro que caracteriza o sítio, sem correlação muito nítida com as várias estruturas funerárias nele também presentes, desenhou-se uma estratégia para investigar se o registro arqueológico se constitui de atividades exclusivamente funerárias, ou outras podem estar ali implicadas - acampamentos de caça e pesca, por exemplo. Assim este artigo busca, por um lado, consolidar a percepção do sítio Galheta IV como espaço dedicado às atividades funerárias (e/ou com elas diretamente relacionadas) e, de outro, interpretar a natureza dos eventos que ali tiveram lugar no contexto da presença Je no litoral, em meio ao que fora, até bem pouco tempo antes, e por milênios, território exclusivamente sambaquieiro.

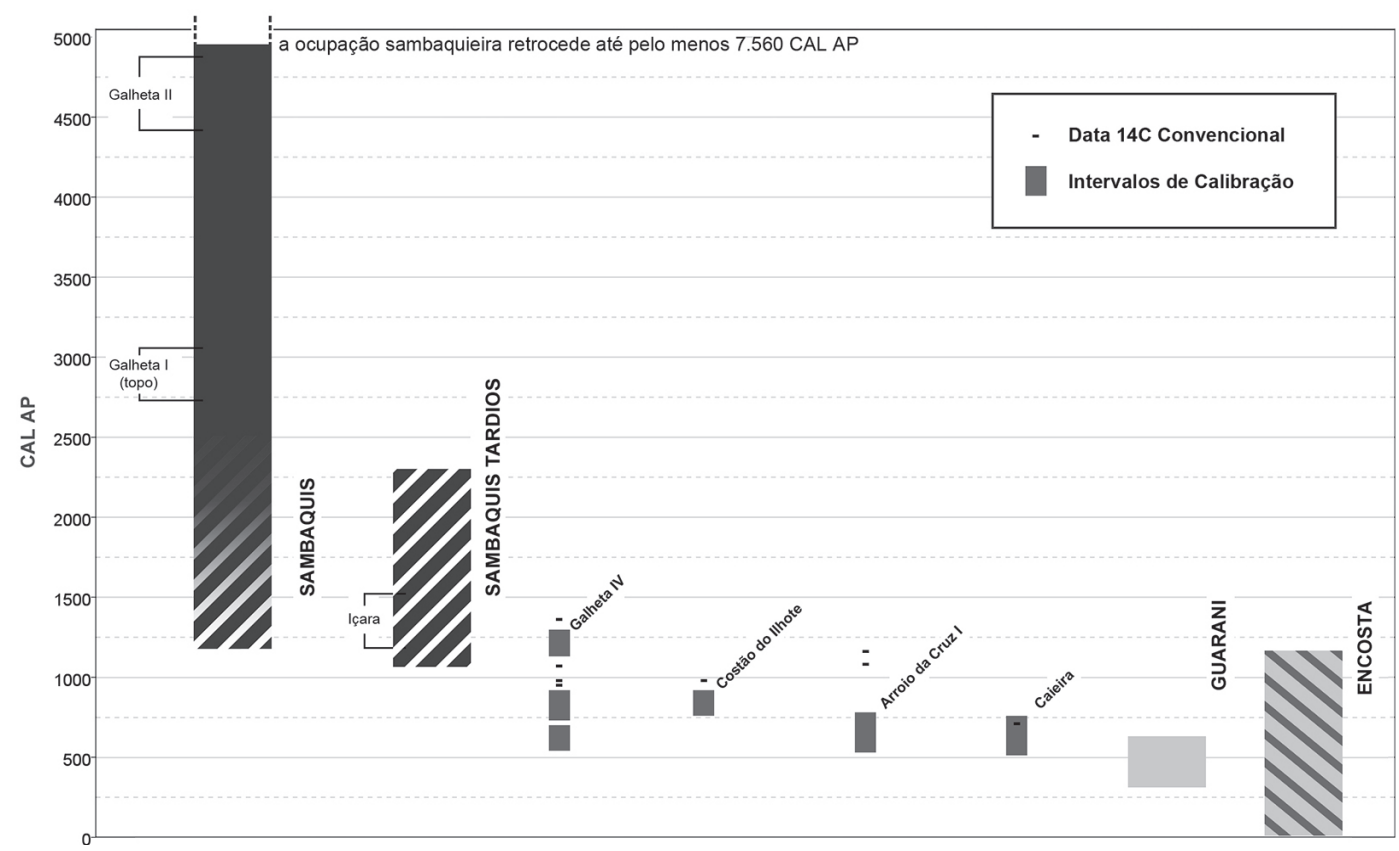

Fig. 4. Cronologia para a região de Laguna, incluindo os sítios proto-Je da encosta adjacente. Datações calibradas no Calib 6.0 (Stuiver e Reimer 1993) usando a curva Marine 09 (Reimer et al 2009) para as amostras de origem marinha e a curva SHCal 04 (McCormac et al 2004) com intervalo de calibração em 2o. As barras largas representam conjuntos de sítios da mesma natureza (sambaquis, sambaquis tardios, Guarani e encosta), e as barras finas representam sítios costeiros Taquara apresentados individualmente. Note-se que a transição dos sambaquis para os sambaquis tardios (representados pelo padrão hachurado) se dá sobre aqueles ao mesmo tempo em que estes últimos aparecem também em outras locações. A ocupação Taquara datada em Caieira é sobre um sambaqui, mas foi plotada aqui como sítio individual, devido ao isolamento em relação ao substrato conchífero reportado por Hurt (1974). As datações de sambaquis e sambaquis tardios aqui utilizadas encontramse em Giannini et al 2010 (exceto Içara, em Schmitz et al 1999), dos sítios Guarani em Milheira e DeBlasis 2011 e da encosta em Farias e Kneip 2010. Gráfico elaborado por Tiago Attorre. 


\begin{tabular}{|l|l|l|l|l|l|}
\hline Sítio & Lab ID & Amostra & CRA & sig & Proveniência \\
\hline Galheta I & Beta 209708 & Anomalocardia & 3090 & 70 & $10-20$ cm, topo do sambaqui \\
\hline Galheta II & Beta 209709 & Anomalocardia & 4400 & 60 & $10-20$ cm, topo do sambaqui \\
\hline Galheta II & CENA LS-10 & Anomalocardia & 4530 & 70 & $\begin{array}{l}\text { base do sambaqui (Giannini } \\
1993)\end{array}$ \\
\hline Galheta IV & Beta 211734 & osso humano & 980 & 40 & sepultamento 1 \\
\hline Galheta IV & Beta 280010 & osso humano & 1360 & 40 & sepultamento 3 \\
\hline Galheta IV & Beta 280011 & lobo marinho & 1070 & 40 & Quadra 112/093, Nível 3 \\
\hline Galheta IV & Beta 280012 & osso humano & 950 & 40 & sepultamento 7 \\
\hline Arroio da Cruz I & Beta 209703 & Mes. mactroides & 1080 & 60 & $\begin{array}{l}\text { sondagem 1, camada central } \\
(50-60 \text { cm) }\end{array}$ \\
\hline Arroio da Cruz I & Beta 211732 & Mes. mactroides & 1160 & 40 & sondagem 1, camada da base \\
\hline Caieira & Isotopes 2624 & carvão & 710 & 95 & $\begin{array}{l}\text { topo de sambaqui com cerâ- } \\
\text { mica (Hurt 1974) }\end{array}$ \\
\hline
\end{tabular}

Tabela 1: Datações dos sítios da Galheta (incluindo Galheta I e II, sambaquis mais antigos) e outros sítios Taquara da região. A datação de Caieira provém de uma ocupação sobre sambaqui. CRA representa a idade radiocarbônica convencional (ver uma perspectiva sinótica das datações calibradas na figura 4).

\section{Sambaquieiros e jes no litoral sul catarinense}

Vistos, por muito tempo, como resultado da ação de bandos de coletores de moluscos e pescadores nômades de tecnologia singela e organização social bastante simples, os sambaquis, estruturas monticulares predominantemente conchíferas (formados, sobretudo, por carapaças de berbigões e ostras), vem sendo reconhecidos como produto de grupos sociais de baixa mobilidade, bem adaptados aos produtivos ambientes litorâneos (Figuti 1993, Scheel-Ybert et al 2009, Gaspar 2000), exibindo padrões demográ- ficos e de organização social mais complexos do que se imaginava (DeBlasis et al 1998, Gaspar et al 2008). Estudos recentes vêm mostrando que os sambaquis são, em grande parte, construções longevas de forte significado simbólico (p. e. Fish et al 2013).

Pesquisas no litoral sul catarinense, sobretudo o estudo detalhado dos padrões deposicionais no sambaqui Jaboticabeira II, mostram que a complexa estratigrafia sambaquieira se relaciona a processos de monumentalização de áreas funerárias através da deposição recorrente e incremental de restos alimentares, em um programa ritualizado de práticas 
funerárias e retorno periódico ao local dos ancestrais, reais e míticos (Gaspar et al 2008, Fish et al 2013). Os sambaquieiros constituiam grandes áreas funerárias coletivas de duração relativamente curta, resultando em pacotes arqueológicos homogêneos contendo sepultamentos numerosos, frequentemente fletidos e, no mais das vezes, com discreta distinção individual. A cremação é totalmente ausente, exceto no período final da ocupação sambaquieira, em torno de 1500 a 1200 anos atrás. Estes locais eram periodicamente fechados (não raro com uma cobertura de conchas) e posteriormente retomados, resultando em uma estratigrafia sequencial e incremental, formada por paleosuperfícies funerárias sobrepostas e entremeadas de pacotes conchíferos de dimensões e espessura variáveis (Fish et al 2000). Estudos zoo e geoarqueológicos, e também antracológicos, dos processos formativos presentes nesse sítio revelam que sua complexa estratigrafia inclui tanto vestígios de festins funerários que ali tiveram lugar, como também materiais redepositados a partir de lugares externos ao próprio sambaqui, configurando uma intrincada sequência de arquitetura monticular, onde áreas habitacionais parecem estar ausentes (Klökler 2008, Bianchini et al 2011, Villagrán et al 2010) ${ }^{3}$.

A cronologia disponível para o litoral meridional catarinense (tabela 1, fig. 4) mostra que a ocupação sambaquieira remonta há pelo menos 7.000 anos AP e se intensifica entre 5 e 2 mil anos atrás aproximadamente, com dezenas de sítios concomitantemente ativos, inclusive os dois sambaquis da Galheta (Kneip 2004, DeBlasis et al 2007, Giannini et al 2010). Estas longevas estruturas funerárias configuram, assim, um ciclo recorrente e incremental, de longa duração, nos mesmos lugares de referência na paisagem lagunar, criando assim estruturas monumentais (Fish et al 2013).

3 Há evidências crono-estratigráficas consistentes de que este padrão funerário de construção sambaquieira é amplamente recorrente na região, ainda que outras variedades de concheiros também tenham sido encontradas (DeBlasis et al 2007, Peixoto 2008, Assunção 2010, Belem 2012).
Por volta de dois mil anos atrás as conchas deixam de ser o principal material presente nas construções monticulares, dando lugar a maciças quantidades de restos faunísticos (peixes, principalmente) e outros materiais orgânicos que geram espessos pacotes da chamada "terra preta de sambaqui” (Nishida 2007, Villagrán et al 2010). Conquanto estes pacotes enegrecidos eventualmente recubram os concheiros mais antigos, paralelamente vão aparecendo sítios constituídos quase que exclusivamente destes materiais orgânicos escurecidos, aqui designados como sambaquis tardios. Neles, estruturas habitacionais também parecem estar ausentes, permanecendo sua construção relacionada a práticas funerárias até seu desaparecimento, por volta de 1200 anos atrás (fig. 4).

Concomitantemente ao momento em que esses sítios vão deixando de ser construídos, outra variedade de sítio aparece, exibindo também pacotes enegrecidos quase sem conchas. Sempre pequenos e levemente convexos, formando discretas "calotas", estes sítios, menos frequentes ao longo da costa, distinguem-se dos anteriores não apenas em termos cronológicos, mas também em função de um perfil faunístico distinto e, sobretudo, pela presença da diagnóstica cerâmica Taquara. Este estudo foca, justamente, um destes sítios, Galheta IV.

A ocupação proto-Je nas terras altas do sul do Brasil, embora presente desde pelo menos dois mil anos atrás, conhece grande expansão no final do segundo milênio, quando passam a exibir estruturas de ocupação mais complexas, incluindo conjuntos de casas subterrâneas e outras estruturas de engenharia de terra (Copé 2007, Beber 2005, Schmitz et al 2010, Corteletti 2012). Embora aparentemente ausente nos sítios mais antigos, a cerâmica Taquara/Itararé é uma característica deste horizonte cultural, estando já bastante consolidada sua relação com o grupo linguístico Je do Sul, etnograficamente reconhecido nos grupos Xokleng e Kaingang do planalto meridional brasileiro (Schmitz 1988, Silva 2001, Noelli 2000). Vários autores se referem à presença de cemitérios comunais em locais altos, com ampla visibilidade, marcados por numerosos montículos que, embora muito próximos, configurando um conjunto articu- 
Velhas tradições e gente nova no pedaço: perspectivas longevas de arquitetura funerária na paisagem do litoral sul catarinense R. Museu Arq. Etn., 24: 109-136, 2014.

lado, geralmente são formados por estruturas funerárias individuais, às vezes geminadas (p.e. Chmyz e Sauner 1971, Araujo 2001).

Nestes cenários ocorrem também estruturas circulares abertas e aplainadas, às vezes com dimensões consideráveis, os danceiros, interpretadas como áreas cerimoniais e não raro associadas também a funções funerárias (Müller 2008, DeMasi 2006). A presença destas estruturas de arquitetura de terra vem sendo associadas a funções integrativas socialmente relevantes em âmbito regional, indicando sistemas de territorialidade e organização social de complexidade considerável (Iriarte et al 2008 e 2012, Copé e Saldanha 2002, Saldanha 2005, Souza e Copé 2011).

Outro cenário em que aparecem vestígios atribuídos aos Je é a encosta da serra catarinense, uma região marcada por morrarias florestadas e vales encaixados, situada entre a escarpa do planalto e a fachada litorânea. Ali ocorrem, nos topos das colinas e, eventualmente, nas várzeas dos vales pequenos e fechados, numerosos sítios arqueológicos pequenos e rasos, caracterizados por manchas escuras contendo materiais líticos dispersos e grandes quantidades de carvão. A cerâmica, bastante rarefeita nesses sítios, consiste de restos de vasilhas pequenas, com decoração lisa, ungulada, beliscada, pinçada, ponteada e estampada (Farias 2010), características associadas à Tradição Taquara. Contra a idéia de que estes grupos seriam caçadores de grande mobilidade (p.e. Lavina 1994, entre outros), Farias (2005) desenvolve um modelo convincente, reforçado por datações em diversos sítios, de que a ocupação Je na encosta representa um padrão de grande estabilidade territorial, marcado por boa adaptação ao ambiente de Mata Atlântica. A cronologia disponível (fig. 4) mostra que esta ocupação alcança o século XX, havendo abundante documentação etnohistórica acerca destes grupos, sob a designação de Xokleng (Farias 2005).

No litoral sul catarinense Rohr (1969, 1984) e Hurt (1974) já haviam detectado vários "sambaquis" com cerâmica Taquara, referidos também por Kneip (2004) e DeBlasis et al (2007), que apontam grande proximidade cronológica entre estes sítios e as datações sambaquieiras mais tardias. São vários os pequenos sítios deste mesmo horizonte, em torno de 1200 a 600 anos atrás (tabela 1, fig. 4), dispersos ao longo da linha de costa que, além da presença distintiva da cerâmica Taquara, exibem também outros sintomas diferentes dos sambaquis "tradicionais", particularmente no que se refere à estruturação estratigráfica (em geral, um só pacote arqueológico) e a composição malacológica e faunística bastante distinta, formados por um volume considerável de restos de peixe e carvão misturados a lentes plenas de conchas de Mesodesma mactroides (marisco branco) e moçambique (Donax sp), espécies raras nos sambaquis, e ainda aves e fauna marinha de grande porte.

Embora alguns destes sítios - como o aqui estudado - sejam exclusivamente funerários (p.e. fig. 5a), outros (p.e. Arroio da Cruz I, também datado) não contêm sepultamentos, parecendo acampamentos ou ocupações temporárias. Estes últimos pontilham as dunas junto às extensas praias que se alongam ao sul em direção à foz do rio Urussanga (Rohr 1984, Kneip 2004) e além, até o litoral setentrional do Rio Grande do Sul (Schmitz 2006). Sítios deste horizonte com características habitacionais ainda não foram localizados, embora Rohr (1969) mencione a presença de casas subterrâneas nas colinas lindeiras à região lagunar. Esta ausência sugere que a ocupação Je litorânea não representa migrações ao longo da costa, mas provavelmente se relaciona com a ocupação densa e consistente na encosta da serra e no próprio planalto adjacente (Farias e Kneip 2010) ${ }^{4}$.

4 Um derradeiro horizonte pré-histórico presente na região refere-se a uma breve - mas intensa - ocupação Guarani, que foge ao escopo deste artigo (a este respeito ver Milheira e DeBlasis 2011). Basta notar, aqui (fig. 4), que a cronologia indica que os grupos Je ainda estavam nesta porção do litoral sul catarinense quando da chegada maciça dos Guarani na região, pouco antes do contato com os europeus. 


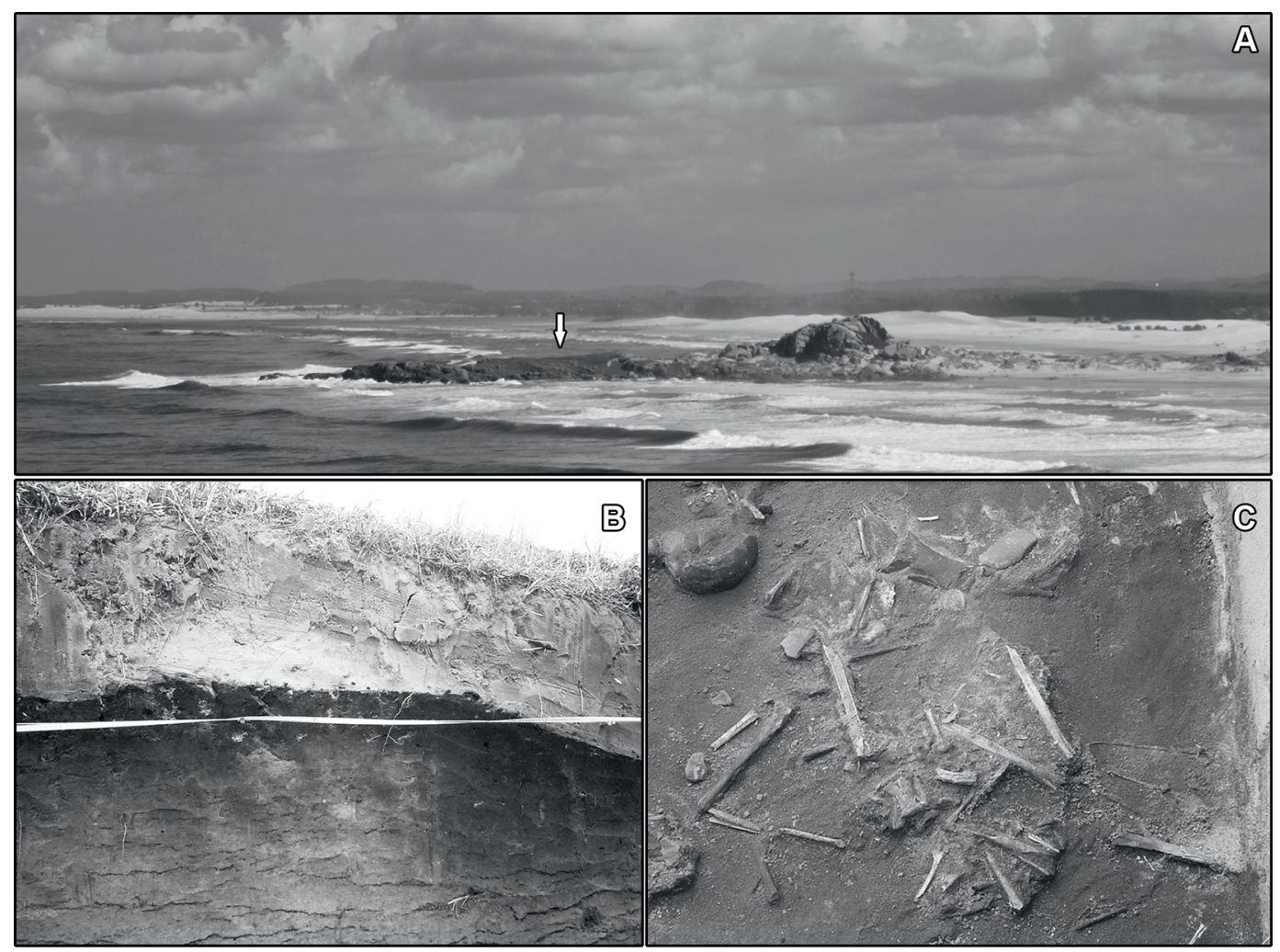

Fig. 5. a) O sítio Ponta do Costão do Ilhote, do mesmo horizonte de Galheta IV, visto a oeste-sudoeste da extremidade do cabo de Santa Marta, onde se encontra o sambaqui Santa Marta II (foto R. Corteletti). b) Perfil mostrando a geometria peculiar da camada escura e redeposição de material orgânico sob a superfície de ocupação arqueológica. c) concentração de fauna na área escavada (fotos D. Farias).

\section{As características do sítio e as intervenções arqueológicas}

O sítio Galheta IV se constitui como uma feição topográfica levemente convexa, monticular, pequena e discreta, pouco notável à primeira vista no cenário volumoso do pontão com seus vizinhos, o agigantado sambaqui da Galheta e o pequeno concheiro situado a seus pés (Galheta II). O sítio se encontra no flanco oeste do pontão, mais rebaixado, assentado em meio a uma sequência de feições dunares hoje estabilizadas, mas contíguas aos cordões de dunas ativas, situados na retro-praia a oeste do pontão, estendendo-se tanto a sul como a norte. O sítio se insere, assim, em um contexto de sedimentação arenosa inconsolidada, permeável e fluída, constantemente fustigado pelos fortes ventos de sul e nordeste, o que ajuda a explicar a dispersão bastante homogênea dos vestígios no pacote arqueológico.

O montículo foi cortado ao meio por uma estrada, expondo um longo perfil que corta quase toda sua extensão, revelando a presença de uma camada escura a cerca de meio metro de profundidade, em meio a uma sequencia de sedimentação arenosa mais clara, de aproximadamente quatro metros de altura no centro do sítio, que repousa sobre o embasamento granítico. Nessa camada escura concentra-se grande quantidade de vestígios faunísticos, carvão e materiais líticos e cerâmicos, que ocorrem também acima dela, aflorando, de maneira rarefeita, à superfície, indicando mobilidade dos vestígios no pacote arenoso. Observouse também, nos perfis e na área escavada, a 
Velhas tradições e gente nova no pedaço: perspectivas longevas de arquitetura funerária na paisagem do litoral sul catarinense R. Museu Arq. Etn., 24: 109-136, 2014.

presença de sepultamentos e outras estruturas (fogueiras e concreções), sempre associadas ao pacote enegrecido, a única camada de ocupação do sítio.

As campanhas de escavação, realizadas entre 2005 e 2007, privilegiaram basicamente duas abordagens. De um lado, a documentação dos perfis estratigráficos presentes nos barrancos existentes no corte da estrada (sentido nordeste/sudoeste) e na porção sul do sítio, aberta por uma vossoroca. Este trabalho permitiu descrever as dimensões e a morfologia do sítio, assim como caracterizar sua natureza monocomponencial, além de possibilitar a detecção dos tipos de estrutura que o compõem. Por outro lado, procedeu-se à abertura de uma superfície ampla de exposição horizontal em sua porção centro-oriental (área A, 32 $\mathrm{m}^{2}$ ), de modo a investigar as características da organização espacial dos vestígios e estruturas nele presentes. Abriu-se ainda uma pequena escavação na porção oeste do montículo (área B, $4 \mathrm{~m}^{2}$ ), em função de restos esqueléticos que afloravam em uma área já um tanto afetada por processos erosivos, junto ao barranco da estrada. Foram escavados, no total, $36 \mathrm{~m}^{2}$, tendo-se evidenciado oito sepultamentos, várias estruturas de combustão associadas a concreções, e grande quantidade de vestígios dispersos de maneira mais ou menos homogênea por toda a camada arqueológica - e além dela, de maneira esparsa (fig. 6).

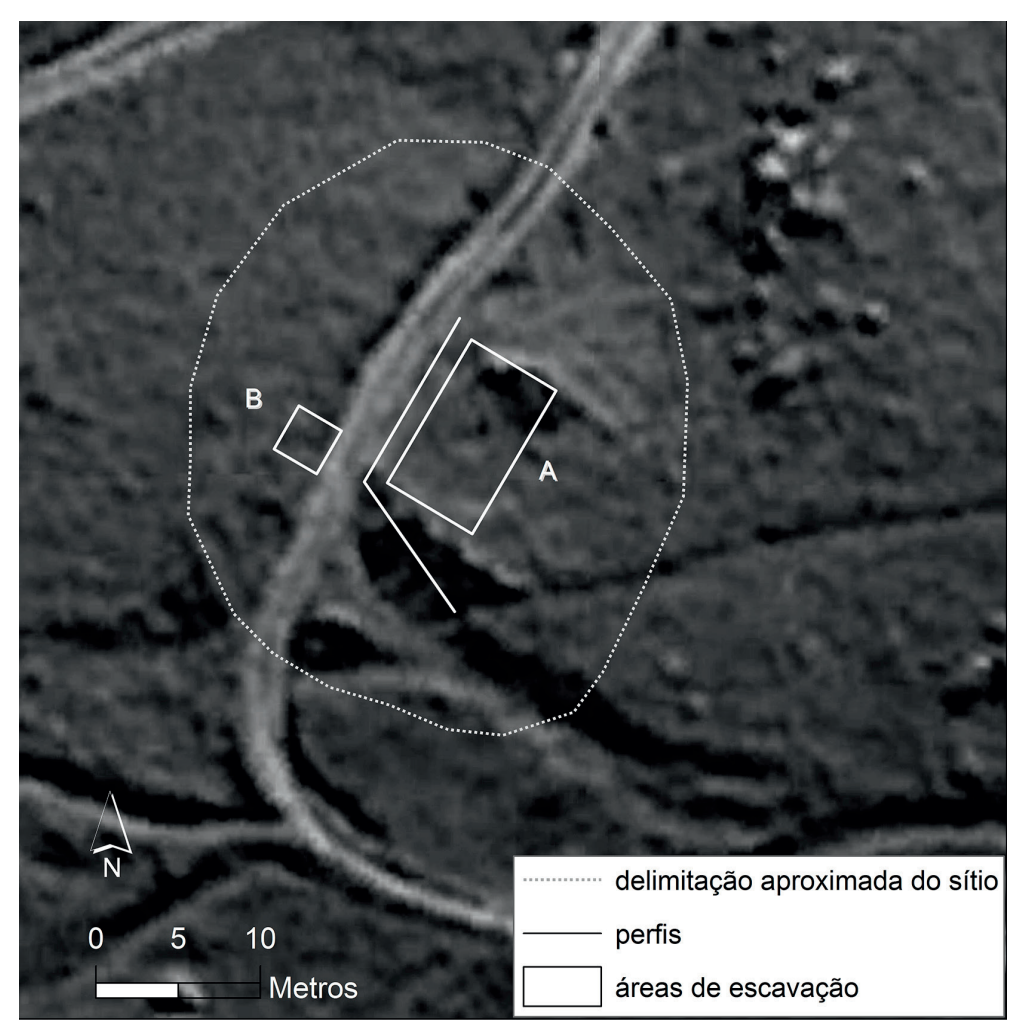

Fig. 6. Localização das intervenções realizadas no sítio Galheta IV (A. Demathé)

A estratigrafia do sítio é constituída por três pacotes sedimentares. A camada superficial, com cerca de 40 a $50 \mathrm{~cm}$ de espessura, é composta de sedimento arenoso de granulação fina, baixa compactação e coloração clara. Trata-se de formação dunar recente, semi-estabilizada pela presença generalizada de gramíneas, interpretação confirmada por uma datação por LOE de $174 \pm 17$ AP obtida de uma amostra de sedimento proveniente de sua porção basal, imediatamente 
acima do pacote arqueológico ${ }^{5}$. Os vestígios arqueológicos que aparecem de maneira esparsa neste pacote não configuram qualquer estruturação, sendo remobilizados a partir da própria camada arqueológica, ou das áreas circundantes.

A segunda camada, o pacote arqueológico propriamente dito, com cerca de $40 \mathrm{~cm}$ de espessura, ocorre, grosso modo, a partir dos $50 \mathrm{~cm}$ de profundidade, em contato abrupto com a camada que a recobre, sinalizando se tratar de uma superfície erodida. Compacta e ininterrupta, sugerindo um mesmo "momento" de ocupação, esta camada é bastante homogênea em termos de coloração e textura, com geometria levemente convexa, acompanhando a inclinação da vertente para oeste/sudoeste. É composta por sedimento areno-argiloso escuro, rico em carvão e materiais orgânicos, no qual se distribui grande quantidade de vestígios - faunísticos, sobretudo - configurando nitidamente um solo de ocupação entre os pacotes de areia depositados naturalmente. Esta camada de ocupação, apesar de bastante deformada pela movimentação dos sedimentos e outros processos pós-deposicionais ${ }^{6}$, ainda guarda resquícios da disposição de estruturas funerárias e de combustão - e também dos próprios vestígios aparentemente dispersos, como se verá adiante. A coloração do sedimento da camada já é, em si, testemunho de intensas atividades envolvendo fogo, sendo de fato abundante a presença de fragmentos de carvão dispersos, além de grande quantidade de rochas queimadas (geralmente granitóides) em decomposição. Grandes concreções repletas de carvões e fragmentos ósseos, não raro carbonizados, se dispõem ao redor dos sepultamentos e em meio a abundantes vestígios faunísticos, líticos e cerâmicos.

5 As datações por LOE (Luminescência Oticamente Estimulada) do projeto Sambaquis e Paisagem foram feitas na Oklahoma State University, sempre com o apoio da FAPESP. Agradecemos ao Prof. Dr. Paulo César F. Giannini e seu grupo a coleta e processamento desta amostra.

6 Há, no sítio, abundantes evidências de zooturbação. Fezes de lebre (Lepus sp) e tocas de tuco-tuco (Ctenomys minutus), tanto no pacote arqueológico como fora dele, são testemunhos eloqüentes desses processos.
O pacote arqueológico se assenta sobre uma espessa camada arenosa mais clara, degradando-se nela em contato fluído. De fato se pode observar, ao longo dos perfis, os efeitos da migração de materiais orgânicos provenientes do pacote arqueológico, redepositados em alinhamentos sucessivos (fig. 5b). Cerca de quatro metros abaixo da superfície, na base deste pacote sedimentar, aparece um sedimento grosseiro (saibro), proveniente da decomposição das rochas graníticas que embasam todo o pontão (acerca das características composicionais e formativas das camadas deste sítio ver Villagrán 2012:281-292).

Os vestígios arqueológicos coletados provêm principalmente da área de escavação $\mathrm{A}$, onde foi possivel examinar seus padrões de distribuição. Ali foram exumados quatro sepultamentos, com algumas estruturas concrecionadas associadas a fogueiras junto a eles, compondo um cenário aparentemente integrado, uma mesma organização estruturada do espaço. Em torno destas estruturas - e em seu interior, como é o caso das concreções - os remanescentes faunísticos e outros materiais dispersos se dispõem, inclusive rochas graníticas queimadas, ossos longos e grandes de mamíferos marinhos e terrestres, boa quantidade de restos de aves, algumas conchas e ossos de peixes - alguns ainda articulados, sugerindo oferendas. Fauna em abundância, associada às concreções e aos sepultamentos, ocorre em toda área escavada; ao término de cada decapagem era possível enxergar um verdadeiro piso de ossos de aves e animais terrestres e aquáticos como albatroz, lobo marinho, pinguim, cetáceos e peixes, não raro queimados (fig. 5c).

As concreções aparecem dispersas por todo o lado leste do sítio, formando feições volumosas e grosseiramente circulares, em torno de 50 a $60 \mathrm{~cm}$ de diâmetro. Pouco resistentes, são compostas de substâncias orgânicas fluídas que, provavelmente em função de exposição ao calor e, na sequência, um leque de efeitos pós-deposicionais, se consolidaram incorporando os vestígios circundantes, uma composição que, além da areia do substrato, inclui grande quantidade de carvão e restos orgânicos, principalmente restos faunísticos, e fragmentos rochosos. Parecem, 
Velhas tradições e gente nova no pedaço: perspectivas longevas de arquitetura funerária na paisagem do litoral sul catarinense R. Museu Arq. Etn., 24: 109-136, 2014.

de fato, resquícios de fogueiras misturados com restos de fauna e outras substâncias orgânicas. Apesar de sua condição última ser fruto de processos pós-deposicionais, a composição é decorrente de atividades realizadas durante a ocupação do sítio envolvendo fogueiras e restos de alimentação, interpretadas como festividades fúnebres (ver discussão adiante).

Os vestígios de sepultamentos humanos estão presentes tanto nas áreas de escavação como nos perfis; situados na porção centro-ocidental, mais alta, do montículo, são eles que, de fato, conferem sentido funcional ao sítio. Em nenhum dos oito sepultamentos registrados (todos adultos, de ambos os sexos) se observou a presença de buracos de estaca, tão comuns nos sambaquis da região (Fish et al 2000, Klökler 2008, Fish et al 2013). Todos estão associados a grande quantidade de fauna e, do lado leste, são contíguos às concreções. Quatro sepultamentos (dois no perfil, um na área A1 e outro em A2) estão completos e articulados, todos fletidos. Seu espaçamento regular sugere que regem a formação de montículos individuais. Marcas ocasionais de queima e corte indicam que mesmo estes sepultamentos inteiros e em conexão anatômica são, também, secundários. Os demais são incompletos, desarticulados e claramente secundários, manipulados; um deles parece ser a deposição final de um indivíduo cremado em outro local. Dois outros parecem indicar alguma associação/sobreposição de eventos funerários com os sepultamentos completos (sepultamentos 1 e 6,2 e 8), quiçá conectados por ligações simbólicas, ou de parentesco. A maior parte destes sepultamentos exibe acompanhamentos funerários, muito evidentes, sobretudo, nos indivíduos em conexão, acompanhados de rochas lisas e artefatos líticos, conchas grandes e vistosas, ossos grandes e dentes de mamíferos marinhos e terrestres, fragmentos e lascas de quartzo e diabásio.

A cerâmica ocorre no sítio em pequena quantidade, bastante fragmentada. Roletada e temperada com areia, tem paredes finas (a grande maioria entre 4 e $8 \mathrm{~mm}$ ) e bem alisadas, por dentro e por fora. Apesar de certo grau de erosão da superfície dos cacos pelo atrito com o meio arenoso onde se encontravam, pode-se perceber que alguns deles exibem a superfície externa brunida. A reconstituição morfológica das vasilhas, quando possível, as mostra pequenas, de forma globular, às vezes com discreta inflexão nas proximidades da borda - quase todas, pequenas cuias e potes característicos da Tradição Taquara (fig. 7a). Raros cacos de parede mais espessos (até $11 \mathrm{~mm}$ ) sugerem a presença de formas um pouco mais volumosas. Fragmentos de base mostram, de novo, vasilhas diminutas e medianas de base convexa (uma delas plana). Ainda que a maioria dos fragmentos tenha paredes lisas, vários deles trazem decoração plástica na face externa, um conjunto variado de impressões dispostas sobre a superficie alisada da vasilha incluindo incisões, pontilhados, ungulados e o que parece ser impressões de cestaria, novamente remetendo à Tradição Taquara (Schmitz 1988, Beber 2005; fig. 7b).

A coleção lítica de Galheta IV, estudada por Fernandes e colaboradores (2011), é composta majoritariamente de fragmentos de pedras queimadas $(83 \%)$, restos de estruturas de combustão e outras atividades envolvendo fogo, predominando rochas granitoides, material localmente disponível (74\%). No restante predominam lascas (cerca de $13 \%$ da amostra) e artefatos (2,6\%), tanto expeditos como polidos, produzidos em rochas básicas, quartzo e arenito. Dentre os artefatos polidos destacam-se pequenos objetos fusiformes, possivelmente adornos, encontrados junto às concreções na porção oriental do sítio (fig. 7c). Encontraramse também lâminas de machado, quebra-coquinhos, mãos-de-pilão, pesos de rede, almofarizes, batedores e afiadores, sempre muito queimados e fragmentados.

A fauna é, sem dúvida, o componente mais abundante e conspícuo em toda a camada enegrecida. Uma parcela da vasta coleção proveniente das escavações, representada por 1733 vestígios faunísticos coletados em uma única quadrícula (113/950), foi analisada por André Osório Rosa, constatando que o Número de Espécimes Ósseos (NISP) se distribui entre peixes (1051, 61\%), aves (541, 31\%), mamíferos (137, $8 \%)$ e apenas 4 répteis. Foram determinados 19 táxons, 4 invertebrados e 15 vertebrados (tabela 2), com o predomínio dos táxons de ambiente 


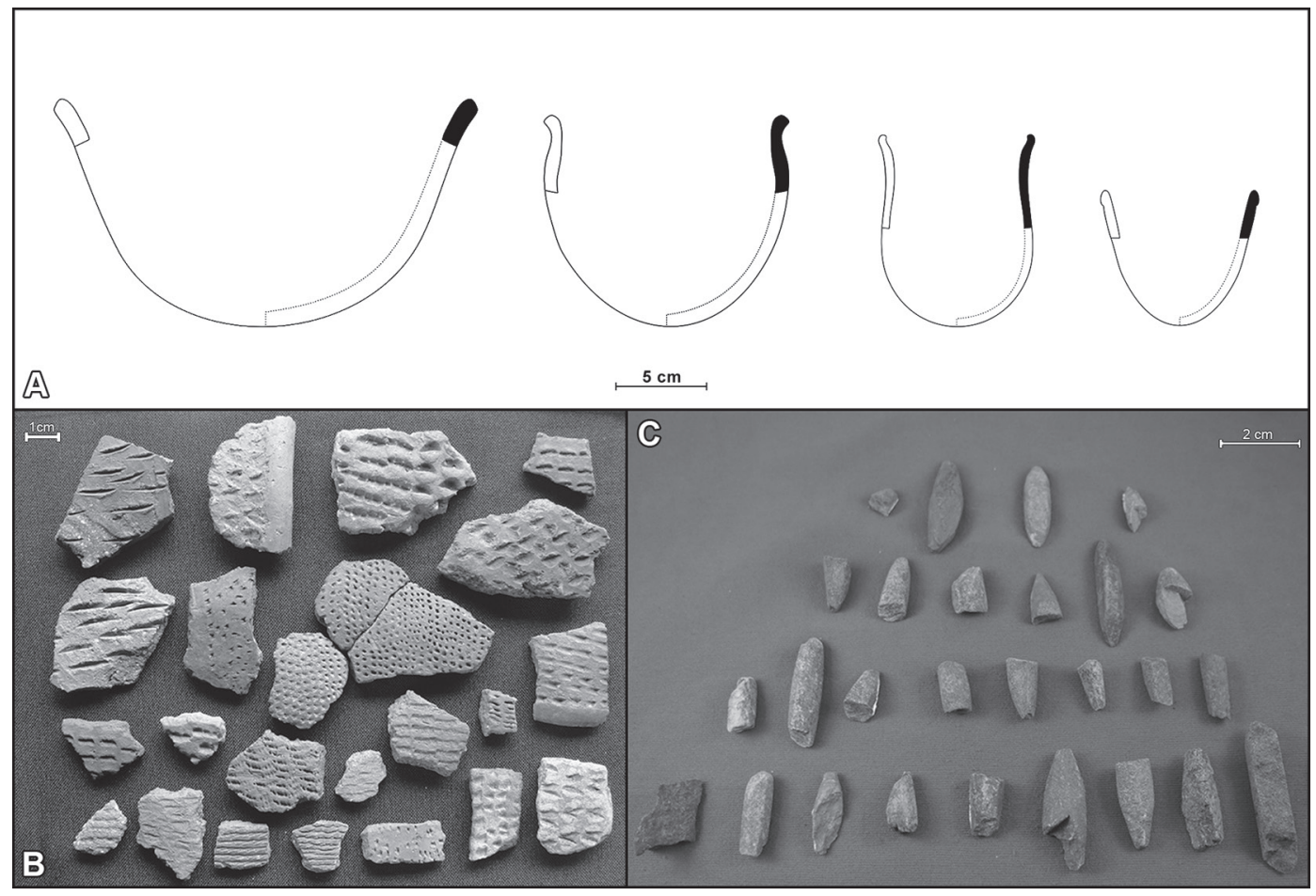

Fig. 7. a) Reconstituição das formas da cerâmica de Galheta IV (K. da Silva). b) Padrões decorativos presentes na cerâmica de Galheta IV (foto P. DeBlasis). c) Adornos encontrados na área central do sítio (foto A. Demathé).

marinho (peixes), seguidos de aves e mamíferos. A corvina (Micropogonias furnieri) é o peixe mais representado. Vestígios de ave são mais comuns na base do sítio (nível 5), com destaque para os albatrozes (Thalassarche sp.). Entre os mamíferos, o lobo-marinho (Arctocephalus sp.) é o táxon mais frequente.

$\mathrm{Na}$ amostra de fauna do sítio Galheta IV estão representados principalmente táxons de comportamento migratório que ocorrem ao longo da costa sul do Brasil entre outono e primavera (sobretudo inverno), a exemplo do pinguim-de-magalhães, albatroz, lobo-marinho e cetáceos (baleias). Nessa amostra observouse também a presença de Olivancillaria vesica auricularia exibindo o característico padrão de quebra encontrado no lábio externo da concha, indicador da utilização do molusco como alimento. As modificações culturais encontradas em ossos longos de albatroz (marcas de corte e polimento) mostram que esses materiais eram utilizados na confecção de instrumentos - dos quais, entretanto, poucos foram encontrados no sítio. Algumas conchas de gastrópodes e bivalves marinhos mostram evidências de utilização como artefatos. Alguns ossos de aves exibem marcas da ação de roedores, reforçando as evidências de bioturbação apontadas mais atrás.

Inferindo padrões deposicionais através de testes estatísticos

Como se viu acima, as escavações evidenciaram grande quantidade de vestígios faunísticos, líticos e cerâmicos. Nas duas primeiras etapas de campo, o registro das coordenadas dos diferentes tipos de objetos encontrados durante a escavação principal (área A) foi feito através de plantas das quadras escavadas em níveis de 10 $\mathrm{cm}$. Na terceira etapa os objetos tiveram suas coordenadas medidas diretamente com o uso 


\begin{tabular}{|l|l|l|l|l|l|l|l|l|l|l|}
\hline & \multicolumn{7}{|c|}{ Níveis } & & & \\
\hline & 1 & 2 & 3 & 4 & 5 & NISP & $\%$ & MNI & $\%$ \\
\hline Chondrichthyes (raias/tubarões) & 16 & & 67 & & 6 & 89 & 23.0 & 1 & 2.3 \\
\hline Ariidae (bagre) & - & - & 18 & - & 2 & 20 & 5.2 & 3 & 6.8 \\
\hline Centropomus sp. (robalo) & - & - & 5 & - & - & 5 & 1.3 & 2 & 4.5 \\
\hline Pomatomus sp. (enchova) & - & - & 8 & - & - & 8 & 2.1 & 3 & 6.8 \\
\hline Sparidae (sargo) & - & - & - & - & 1 & 1 & 0.3 & 1 & 2.3 \\
\hline Micropogonias furnieri (corvina) & 21 & - & 104 & - & 1 & 126 & 32.6 & 15 & 34.1 \\
\hline Pogonias cromis (miraguaia) & 1 & - & 3 & - & - & 4 & 1.0 & 1 & 2.3 \\
\hline Mugil sp. (tainha) & - & - & 1 & - & - & 1 & 0.3 & 1 & 2.3 \\
\hline Chelonia (cágado) & 2 & - & 1 & - & 1 & 4 & 1.0 & 1 & 2.3 \\
\hline Spheniscus magellanicus (pinguim) & - & - & 7 & - & - & 7 & 1.8 & 1 & 2.3 \\
\hline Thalassarche sp. (albatroz) & 34 & - & 44 & & 19 & 97 & 25.1 & 8 & 18.2 \\
\hline Procellariformes indet. (ave marinha) & - & - & 6 & - & 1 & 7 & 1.8 & 2 & 4.5 \\
\hline Arctocephalus sp. (lobo-marinho) & 1 & 1 & 6 & - & 2 & 10 & 2.6 & 2 & 4.5 \\
\hline Cetacea (baleia) & - & - & - & - & 6 & 6 & 1.6 & 1 & 2.3 \\
\hline Mazama sp. (veado) & - & - & - & - & 1 & 1 & 0.3 & 1 & 2.3 \\
\hline Ozotocerus bezoarticus (veado-campeiro) & - & - & - & - & 1 & 1 & 0.3 & 1 & 2.3 \\
\hline TOTAL & 75 & 1 & 270 & & 41 & 387 & 100.0 & 44 & 100.0 \\
\hline
\end{tabular}

Tabela 2: Táxons identificados na amostra faunística analisada.

de uma estação total. As plantas das quadras produzidas durante as duas primeiras etapas foram escaneadas e importadas para o Sistema de Informação Geográfica GRASS (GRASS Development Team 2010, Neteler e Mitasova 2004), sendo em seguida referenciadas, marcando-se os pontos correspondentes a cada objeto encontrado nas seguintes categorias: ossos humanos, concreções, restos faunísticos, conchas, líticos, cerâmica e ocre. Os dados coletados na terceira etapa foram exportados da estação total, incorporados ao GRASS e combinados com os das etapas anteriores, de modo a obter um mapa vetorial de pontos para o total dos objetos encontrados nas escavações. $\mathrm{O}$ mapa vetorial foi importado pelo software $\mathrm{R}$, usando o pacote spgrass6 (Bivand 2007). Finalmente, foi criado um padrão de pontos usando-se o pacote spatstat (Baddeley e Turner 2005). Considerando o formato da área escavada $(4 \times 7 \mathrm{~m})$, criou-se assim

\begin{tabular}{|l|c|c|c|c|c|}
\hline Categorias & Cerâmica & Concha & Fauna & Lítico & Total \\
\hline Número de peças & 225 & 140 & 1344 & 1032 & 2741 \\
\hline Média $\left(\right.$ por $\left.\mathrm{m}^{2}\right)$ & 8.04 & 5 & 48 & 36.9 & 24.48 \\
\hline
\end{tabular}

Tabela 3: Dados utilizados na análise estatística dos vestígios da área de escavação A. 

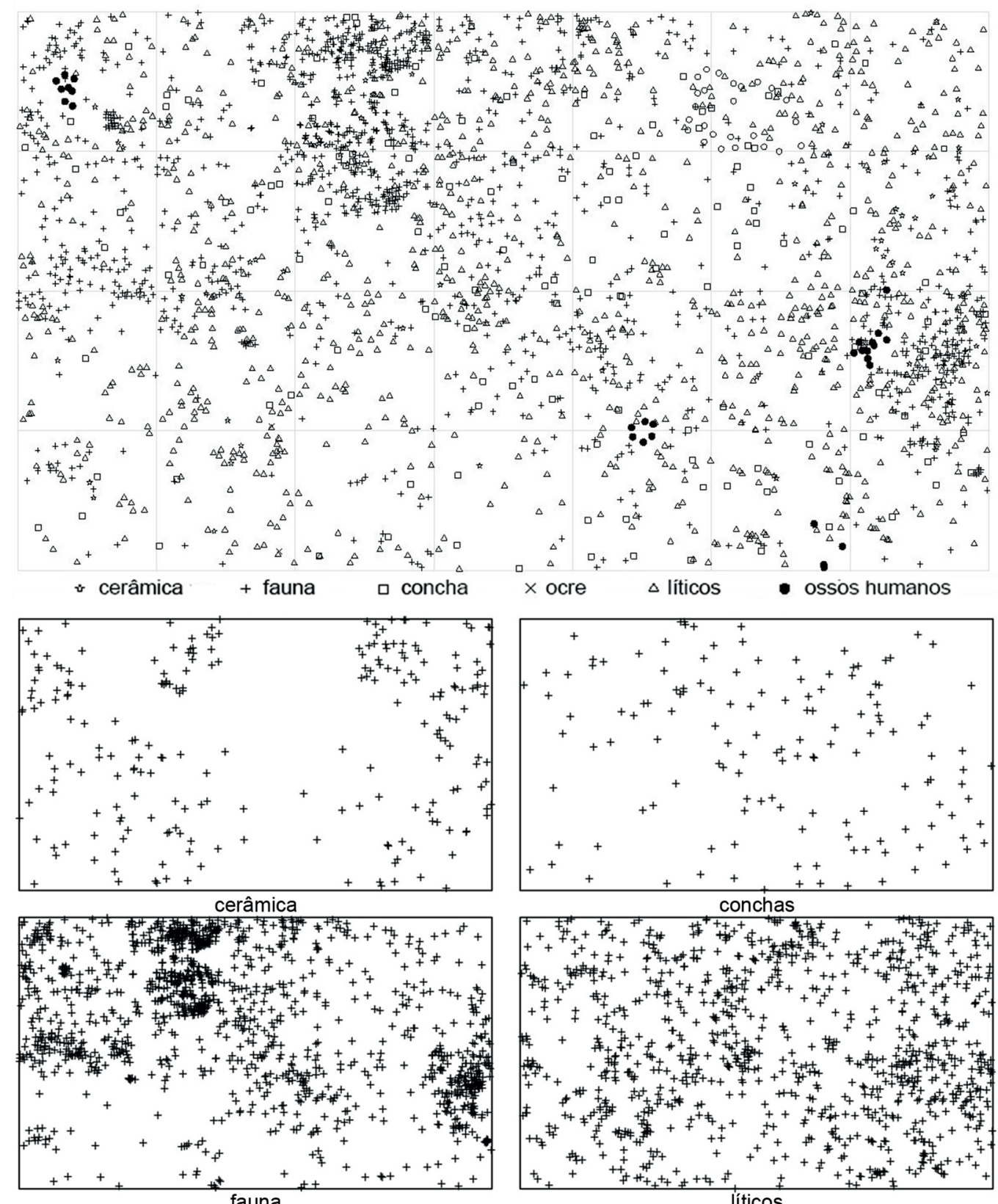

Fig. 8. Acima observa-se a distribuição bidimensional dos vestígios arqueológicos na área escavada de $28 \mathrm{~m}^{2}$. Abaixo, a distribuição em separado dos vestígios líticos, faunísticos, cerâmicos e conchíferos (A. Kneip).

uma "piscina de pontos" de $28 \mathrm{~m}^{2}$, suficientemente grande para testar as relações entre os diferentes vestígios do sítio (fig. 8, superior). $\mathrm{Na}$ tabela 3 são apresentados os dados básicos utilizados na análise estatística.
Era já intuitivamente perceptível, durante as escavações, que tanto a fauna quanto os líticos se adensavam em alguns setores da área escavada, fenômeno menos óbvio para as conchas e fragmentos cerâmicos. Essa percepção aparece 
Velhas tradições e gente nova no pedaço: perspectivas longevas de arquitetura funerária na paisagem do litoral sul catarinense R. Museu Arq. Etn., 24: 109-136, 2014.

na mera inspeção visual dos vestígios em separado (fig. 8, inferior), sendo reforçada com o uso de um método básico de descrição da distribuição diferencial de pontos conhecido como Kernel gaussiano (Bailey e Gatrell 1995), cujos resultados podem ser vistos na figura 9. Pode-se notar, nessa figura, que as curvas para cerâmica, fauna e líticos exibem picos acentuados bem isolados, enquanto que as curvas para conchas representam uma superfície mais suavemente ondulada. Os picos para cerâmica ocorrem em locais coincidentes ou próximos aos picos para fauna, sendo menos clara a relação entre os picos de cerâmica e fauna com os de líticos. Assim, apesar da ubiquidade dos vestígios por todo o pacote, reforçando a sensação de dispersão ampla e homogênea, é possível perceber que sua distribuição exibe zonas de adensamento, nem sempre coincidentes entre os tipos de vestígio.

O problema aqui, entretanto, é não apenas descrever com acurácia os padrões de dispersão dos objetos, mas, sobretudo, sua estruturação espacial; em especial, entender se as áreas de adensamento dos vestígios presentes no sítio se articulam aos sepultamentos, ou representam áreas de atividade não diretamente relacionadas ao contexto funerário (uma área de acampamento, por exemplo). Para isso, uma série de testes estatísticos foi aplicada aos dados provenientes da área de escavação A, com o objetivo de (1) verificar as características distributivas dos vestígios (faunísticos, líticos, conchas e fragmentos cerâmicos), e (2) se estes exibem alguma interação. Outro conjunto de testes verifica se os eventuais aglomerados observados apresentam covariação com os sepultamentos (que configuram três feições distintas, os sepultamentos 2/8, 5 e 7).

Um padrão espacial de pontos pode ser analisado sob dois aspectos fundamentais, intensidade (número de pontos por unidade de área) e regularidade, isto é, se os pontos tendem a se agregar ou repelir. Alguns métodos usam contagem de eventos em uma dada área (análises de densidade), enquanto que outros analisam a distância entre os pontos. $\mathrm{O}$ interesse básico no estudo do padrão espacial de pontos é determinar se existe alguma forma de organização, isto é, se o padrão exibe tendência à regularidade ou à aglomeração. Se um evento inibe a ocorrência dos demais, a tendência da distribuição de pontos é ser regular; se os atrai, tende a um padrão aglomerado. Se os pontos são indiferentes entre si, o padrão exibe tendência à aleatoriedade.

Outra questão que se coloca é se a presença de um determinado objeto (ou feição) atrai ou repele a ocorrência de outro tipo de objeto por exemplo, se os fragmentos líticos e restos faunísticos "são atraídos por", isto é, relacionam-se com, os sepultamentos. Aqui, de novo, a distribuição de pontos pode exibir atração, repulsão ou indiferença. Assim, checar estatisticamente se (e o quanto) um dado padrão se aproxima ou se afasta de um padrão ideal perfeitamente aleatório (dito Aleatoriedade Espacial Completa) é uma maneira eficiente de detectar e distinguir com clareza se tal padrão mostra agregação ou regularidade (para uma descrição destes métodos estatísticos ver Bailey e Gatrell 1995 e Diggle 2003).

Foi primeiramente usado, neste estudo, o teste de $X^{2}$ de Pearson (ou chi quadrado), que usa a contagem de pontos por quadrats para verificar o afastamento que uma determinada distribuição tem de uma distribuição uniforme. Um valor de $X^{2}$ muito pequeno ou muito grande indica tendência à regularidade ou agregação respectivamente, sendo o valor $\mathrm{p}$ ( $p$-value) associado à significância do teste. Para este teste foi usado um quadrat de um metro de lado, coincidente com as quadras escavadas, para cerâmica e concha. Para fauna e líticos cada quadra foi subdividida em 9 e 4 quadrats, respectivamente (a dimensão dos quadrats relaciona-se com o número de ocorrências). Em cada caso foi seguida a regra conservadora do número esperado de

\begin{tabular}{|l|l|c|c|}
\hline Tipo de vestígio & \multicolumn{1}{|c|}{$\chi^{2}$} & \multicolumn{1}{c|}{ df } & \multicolumn{1}{c|}{$p$-value } \\
\hline Cerâmica & 218.89 & 27 & $<2.2 \mathrm{e}-16$ \\
\hline Concha & 38 & 27 & 0.07786 \\
\hline Fauna & 2554.9 & 251 & $<2.2 \mathrm{e}-16$ \\
\hline Lítico & 380.59 & 111 & $<2.2 \mathrm{e}-16$ \\
\hline
\end{tabular}

Tabela 4: Valores de $\chi^{2}$ para as diferentes categorias de vestígios da área escavada ( $\mathrm{df}=$ graus de liberdade). 
eventos dentro de cada quadrat seja no mínimo cinco (Diggle 2003:24). O resultado pode ser visto na tabela 4.

Como se pode ver pelo valor $\mathrm{p}$, o teste mostra que se pode rejeitar a hipótese nula (isto é, que a distribuição é aleatória) para cerâmica, fauna e lítico, mas não para as conchas, com um nível de significância de 5\%. Este último resultado deve ser tomado com cautela, uma vez que o valor $\mathrm{p}$ é muito influenciado pelo tamanho da amostra (Altman e Bland 1995, Diggle 2003:24). Assim, como se vê na tabela acima, os valores elevados de $X^{2}$ para fauna, cerâmica e líticos mostram que estes materiais tem uma distribuição não aleatória, formando, portanto, aglomerações na área escavada, substanciando a percepção visual produzida pelos mapas de densidade Kernel apresentados na figura 9. As conchas aparentam distribuição aleatória.

Outro método usado aqui é o de distribuição cumulativa. Para a inferência estatística é necessário gerar certo número de simulações do padrão aleatório com os mesmos parâmetros (área coberta e número de eventos) da distribuição em estudo. Quando colocadas em um gráfico estas simulações determinam uma

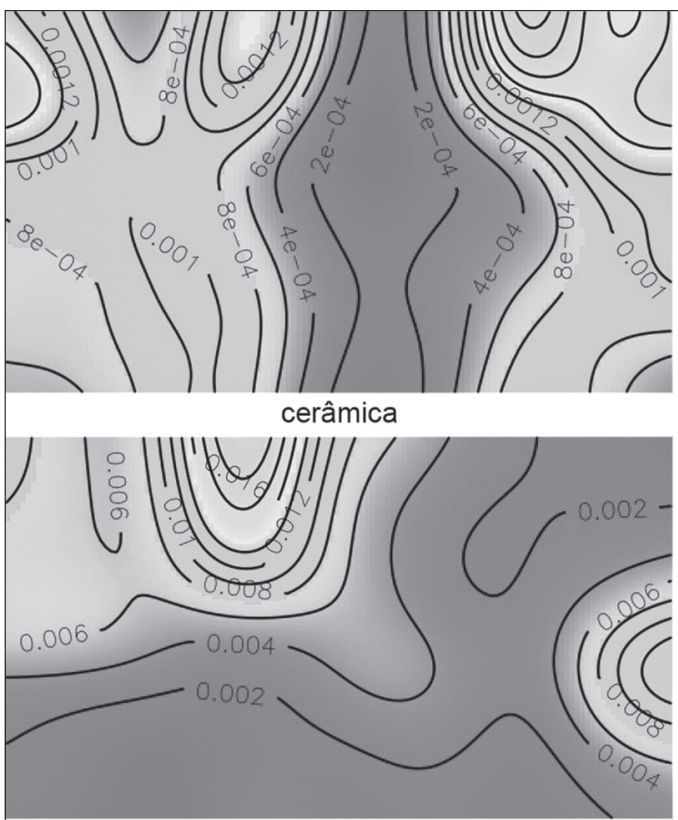

fauna região, chamada envelope, delimitada pelas curvas mais superior e mais inferior obtidas. Se a curva calculada a partir dos dados reais estiver dentro desse envelope, a aleatoriedade espacial completa não pode ser rejeitada. $\mathrm{O}$ número de simulações utilizadas determina o intervalo de confiança do teste. Os envelopes foram gerados através de 39 simulações de aleatoriedade usando o método Monte Carlo, o que dá um nível de significância para os testes de 95\% (para detalhes ver Ripley 1977 e Diggle 2003).

Neste estudo, a aplicação dos métodos de distância busca esclarecer a relação entre conchas, fauna, líticos, cerâmica e sepultamentos (fig. 10). Na primeira linha, o primeiro gráfico mostra que a cerâmica exibe tendência à agregação. $\mathrm{O}$ segundo mostra a correlação entre cerâmica e conchas covariando apenas para uma faixa de valores, entre 45 e $70 \mathrm{~cm}$. O terceiro gráfico mostra covariância entre cerâmica e fauna, em qualquer circunstância. O quarto diz o mesmo no que se refere à cerâmica e os líticos. O quinto gráfico informa que a relação parece ser excludente entre cerâmica e sepultamentos (ver discussão adiante). Na segunda linha observa-se que as conchas exibem tendência à

Fig. 9. Mapas de densidade Kernel dos vestígios na área de escavação A, produzidos pelo software R (A. Kneip). 
aglomeração acima de $65 \mathrm{~cm}$, covariando com a fauna de maneira intensa. Já com os líticos e os sepultamentos, sua distribuição é aparentemente aleatória. Na terceira linha a fauna mostra tendência à aglomeração, qualquer que seja a distância considerada, covariando ainda com os líticos em qualquer que seja a escala, e com os sepultamentos a partir de $30 \mathrm{~cm}$. Na quarta linha observa-se que os líticos apresentam ten- dência à agregação, covariando com os sepultamentos a partir de $40 \mathrm{~cm}$. Por fim, na quinta linha, percebe-se que os sepultamentos mostram também agregação com os demais vestígios, sobretudo a fauna e os líticos.

Os resultados obtidos nas análises estatísticas mostram não apenas a presença de padrões de agregação nos vestígios (isto é, sua distribuição não é homogênea), como também sua
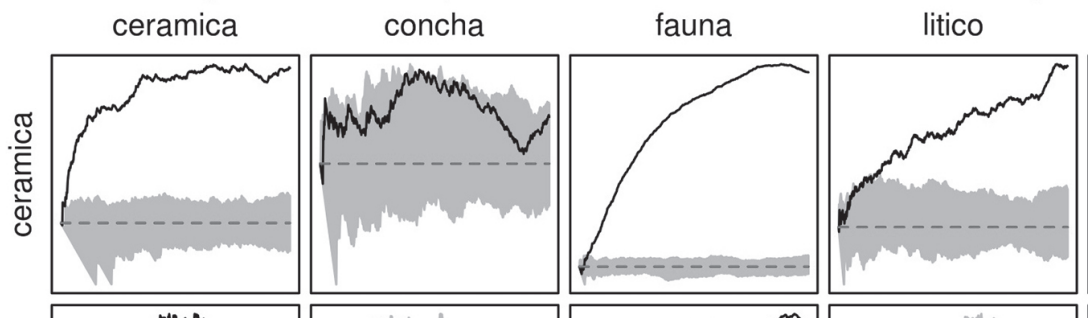

sepultamento
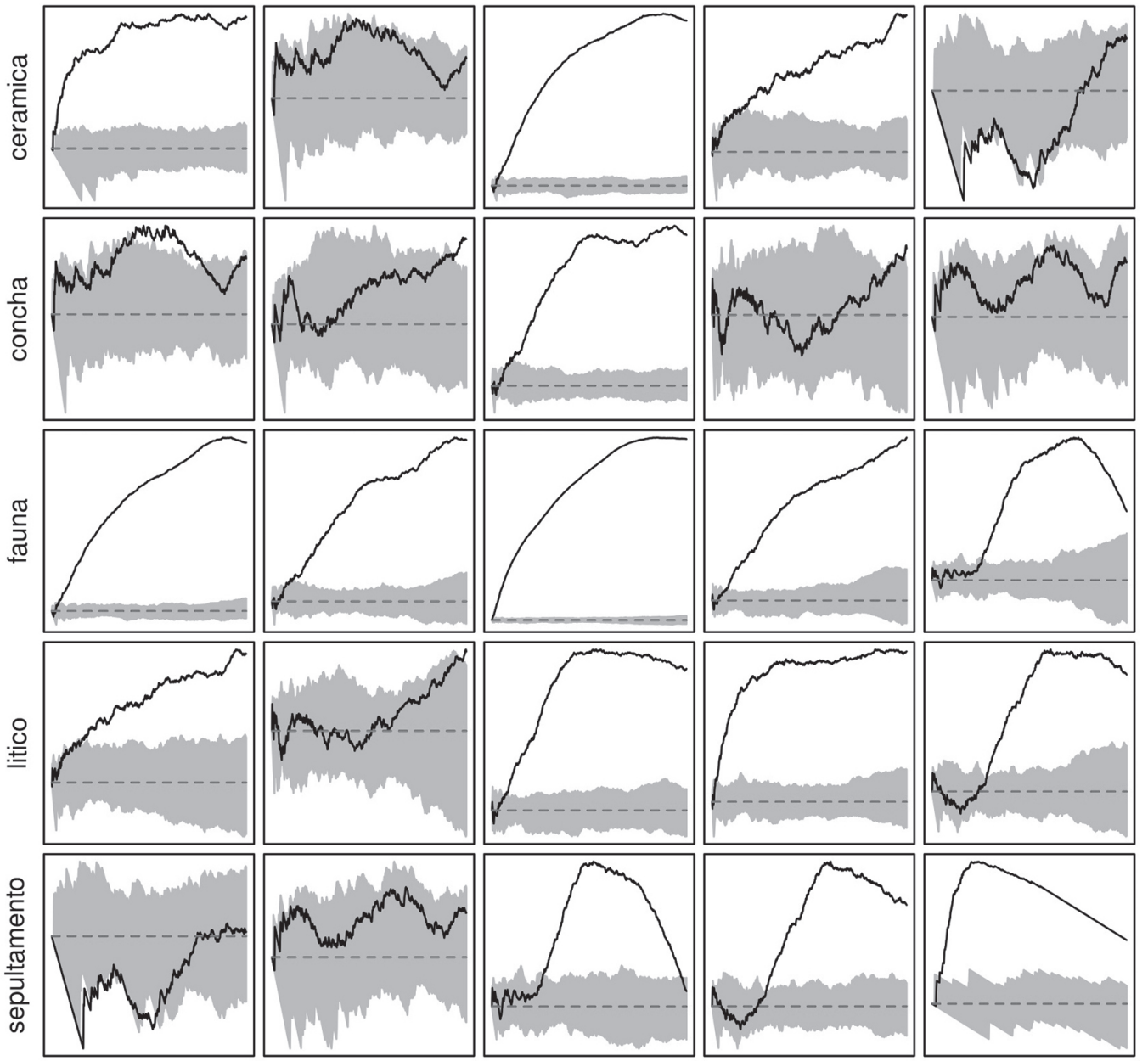

Fig. 10. Matriz de gráficos da função $L$ para pares de categorias de vestígio arqueológico provenientes da área de escavação A. Cada gráfico mostra o envelope de simulações (área em cinza), o resultado para a distribuição aleatória (linha tracejada) e a distribuição real dos eventos (linha contínua preta). Quando o gráfico correlaciona categorias diferentes, está a descrever a covariância entre elas, manifesta quando a linha preta está acima do envelope. Quando examina uma categoria contra ela mesma, a linha preta acima do envelope mostra tendência à agregação, enquanto que, estando abaixo dele, indica regularidade. Quando dentro do envelope, a aleatoriedade da distribuição dos eventos não pode ser descartada (A. Kneip). 
associação estrutural com as feições funerárias, ou seja, estas últimas parecem mesmo "explicar" a distribuição dos vestígios no sítio, suportando a interpretação de que se está diante de remanescentes de rituais funerários envolvendo o consumo conspícuo de alimentos. Os vestígios líticos - que, como se viu, são principalmente restos de estruturas de combustão - se articulam às concreções, e os poucos artefatos participam seja tomando parte nas atividades fúnebres, seja integrando o mobiliário funerário. Por fim, a distribuição aparentemente casual das conchas, dispersas por toda a área do sítio (o que, em menor escala, também ocorre com os fragmentos cerâmicos), talvez possa ser explicada pela pouca quantidade desses itens e seu grau elevado de fragmentação, gerando elementos leves e de fácil mobilidade no sedimento fluído do substrato arenoso, resultando assim em uma distribuição estatisticamente aleatória - a mesma que, à primeira vista, parece afetar todos os vestígios do sítio.

\section{A natureza funerária de Galheta IV}

\section{A interpretação de que Galheta IV é} um local de natureza cerimonial e funerária é reforçada por outros aspectos do registro arqueológico. O primeiro deles é a percepção de que o pacote arqueológico enegrecido que hoje constitui uma superfície convexa e aplainada, é de fato, resultado da movimentação dos sedimentos fluídos do sítio. Sutis discordâncias na orientação da camada arqueológica foram percebidas na tridimensionalização dos perfis documentados no sítio, subsistindo também discretas protuberâncias na geometria convexa da superfície superior da camada arqueológica, interpretadas como remanescentes de pequenas feições monticulares (fig. 6b). Estas evidências mostram que o sítio, originalmente formado por montículos individualizados, teve os sedimentos dispersados e amalgamados com o tempo, formando o pacote aparentemente homogêneo encontrado pelos arqueólogos. $\mathrm{O}$ contato abrupto com a camada acima, de datação bem posterior, reforça a interpretação de que se trata de uma paleosuperfície bastante erodida. Como as estruturas de combustão (concreções) concentram-se na porção oriental, mais rasa e periférica, do mound, o espaço se organiza na forma de montículos funerários na parte central, mais elevada, do sítio, e áreas de feasting na porção mais aplainada vertente acima, na periferia da zona de concentração dos montículos.

Sepultamentos configurando montículos individuais (às vezes com partes de outros indivíduos) são característicos do registro arqueológico relacionado à Tradição Itararé (Chmyz e Sauner 1971, Beber 2005), contrastando com as áreas funerárias coletivas frequentemente encontradas nos sambaquis - embora, nestes últimos, estruturas monticulares pequenas e discretas tenham também sido registradas (p.e. Fish et al 2013:131, figura 7.7). Montículos funerários associados a estruturas arquitetônicas de terra, interpretadas como locais de uso festivo e cerimonial com função comunal e integrativa, também são reportados em sítios proto-Je no altiplano meridional (Iriarte et al 2008 e 2012, Copé e Saldanha 2002, Saldanha 2005, Souza e Copé 2011, Corteletti 2012).

Outro aspecto é a natureza diminuta, bem acabada e bastante decorada, das vasilhas cerâmicas encontradas no sítio. Não são peças associadas ao uso cotidiano, mas utensílios de uso cerimonial. O registro etnográfico Kaingang documenta a deposição de pequenos potes junto ao morto, contendo alimentos para a viagem ao além (ver discussão adiante). DeBlasis (2000) reporta, no interior de montículos escavados no planalto meridional paulista, datados em torno de 900 AP, a presença de fragmentos cerâmicos de pequenos potes Itararé com a superfície externa intensamente brunida, em meio a grande quantidade de carvão e restos orgânicos.

As conchas, fragmentadas e dispersas, encontram-se contextualizadas na forma de oferendas funerárias, como parece ser o caso do conjunto de exemplares de Lucina encontrado nas proximidades do sepultamento 5 . $\mathrm{O}$ mesmo vale para os poucos artefatos líticos formais, quase todos polidos, interpretados como parte do mobiliário funerário espraiado no sedimento arenoso. A fauna abundante, associada às estruturas de combustão (concreções) pontilhadas por fragmentos rochosos queimados, 
Velhas tradições e gente nova no pedaço: perspectivas longevas de arquitetura funerária na paisagem do litoral sul catarinense R. Museu Arq. Etn., 24: 109-136, 2014.

aponta para a presença de festividades fúnebres que evocam a comensalidade como fenômeno de construção do tecido das relações sociais (Jones 2007).

O contexto arqueológico de Galheta IV evoca, de maneira muito vívida, não apenas as estruturas funerárias descritas para sítios da Tradição Taquara/Itararé, mas também os registros de práticas rituais fúnebres de caráter comunal e festivo disponíveis na etnologia dos grupos Je do Sul, compiladas por diversos autores (Müller 2008, Ribeiro 2002, Farias 2005, Veiga 2000 e 2006, Noelli 2000, entre outros). Vamos examinar, muito sinteticamente, alguns aspectos de interesse das práticas funerárias Je etnohistórica ou etnograficamente documentadas (os itálicos, no texto a seguir, destacam semelhanças singulares com o registro arqueológico de Galheta IV).

Segundo Becker (1995) e Müller (2008), os enterramentos Kaingang eram primários, em covas rasas, com as pernas fletidas e envoltos em ponchos, e sobre eles erguiam-se montículos de terra. Mabilde (1988) reporta que, entre os Kaingang, o corpo era coberto por terra até formar um túmulo circular com até seis palmos de altura. Após o sepultamento as mulheres acendem fogueiras a cada dois metros, em uma área circular, e ai cantam e fazem refeições em honra ao morto. Junto eram enterrados seus pertences e a seus pés se colocava um tição de fogo aceso e uma vasilha com alimentos, reabastecida pelos parentes por dias. Becker (1995:265) indica que "a sepultura é periodicamente visitada para renovação da cobertura e para a execução de um rito em memória do falecido, que inclui lamentos, danças, cânticos e bebidas". Müller (2008:35) informa que os Xokleng mantinham o ritual "mesmo após o enterro, sendo que de $15 \mathrm{em} 15$ dias, durante cerca de um ano, o grupo vai chorar o falecido". Como se vê, o paralelo com o registro arqueológico, pleno de carvão, restos de pequenas vasilhas cerâmicas e fogueiras circundando os montículos, impressiona.Veiga (2004) reafirma a importância do ritual funerário e o apresenta como ponto fundamental da festa do kikikoi (em que se consome uma bebida fermentada feita de mel, água e milho, o kiki), organizada pelos familiares diretos em homenagem aos seus mortos recentes. Segundo esta autora "a festa parece ser uma oportunidade dos espíritos dos mortos poderem voltar ao contato dos vivos" (2006:179). Na área da festa várias atividades bastante ritualizadas são realizadas ao longo de vários dias envolvendo a feitura de fogos, a produção do kiki em artefatos especiais para este fim, bebidas, moquéns, rezas e danças, introduzindo-se, a certa altura, convidados das outras aldeias, inclusive das aldeias dos espíritos dos mortos. Ainda segundo Veiga (2004:281), esse ritual expressa que a vida da aldeia depende do destino dos mortos, porque "a sociedade dos vivos é eternamente recriada pelos ancestrais mortos, nossos troncos, nossos antigos".

Há pouca documentação etnográfica sobre o tratamento dos mortos entre os Xokleng. Henry (1964) traz relatos acerca dos rituais de cremação no planalto, e Santos (1973) descreve as práticas de cremação entre os grupos que habitaram da serra catarinense até o início do século XX. O ritual de iniciação dos meninos e meninas parece permear o ritual para os mortos, e para essas festas vinham pessoas de vários lugares e a mata em volta era aberta para as comemorações e danças (ver revisão em Farias 2005). Segundo Montoya (apud Schmitz et al 1999), a prática da cremação, com variações, também estava presente entre os Gualachos. Gakran (2005:23) afirma que "no passado, os mortos adultos eram cremados e seus restos mortais colocados em um cesto e enterrados". Sobre sepultamentos secundários sabe-se que os índios coroados desenterravam os ossos do chefe e os enterravam em outro lugar, quando realizavam uma grande festa para a transladação dos ossos, com festejos e danças sobre a cova, o que resultava em um solo enegrecido (Muller 2008, Becker 1995).

Em síntese, tende-se a considerar que os sepultamentos Kaingang são tipicamente enterramentos primários em montículos de terra, que são periodicamente aumentados, ou mantidos, e entre os Xokleng é característica a cremação total ou parcial do indivíduo, com o sepultamento das cinzas com terra, criando pequenos montículos. Em ambos os casos há o tratamento cerimonial do corpo e os acompanhamentos funerários são semelhan- 
tes, com alimentos, fogo (fogueiras ou tochas), vasilhas cerâmicas e pertences. A manipulação dos corpos e eventual incorporação de partes de outros indivíduos em um novo contexto sepulcral também estão presentes em ambos os grupos. Em ambos, é nos rituais funerários que se dá a ligação da morte com a vida, pois as festas rituais de iniciação se mesclam com o culto aos mortos, e é esse momento, esse limiar, que torna possível os contatos entre os vivos e os espíritos dos mortos. Ali, onde se estabelece formalmente a transição da vida para a morte, também se produz a continuidade da vida através de movimentos de resignificação social. Nesse momento que o grupo homenageia os mortos também inicia os jovens no mundo dos vivos, utilizando os nomes dos mortos e suas prerrogativas (Müller 2008, Ribeiro 2002, Farias 2005, Veiga 2000 e 2006, entre outros).

Neste sentido, talvez os adornos encontrados na zona central do sítio - ali dispostos cerimonialmente, como um cache - se relacionem não com algum sepultamento específico, mas com cerimônias - como a iniciação dos meninos - que tiveram lugar nesse espaço consagrado. Os rituais de morte e vida estão intrinsecamente relacionados: o ritual de iniciação dos meninos e meninas dos Xokleng, e o veingréinyã e o kikikoi dos Kaingang. Esses rituais ocorrem no espaço da aldeia e nos cemitérios, situados estes últimos sempre fora da área habitacional - aspecto que, de novo, encontra perfeita correlação em Galheta IV.

No entanto, deve-se evitar o uso do registro etnográfico como uma camisa de força. Os estudos recentes sobre a ocupação protoJe no sul do Brasil vêm revelando bastante diversidade cultural, grande demais para se limitar a comparações dicotômicas rígidas com os Kaingang e Xokleng do final do século XIX em diante, distantes no tempo e já um tanto afetados pelo contato com o mundo dos brancos. Ainda que tais analogias sejam potencialmente construtivas da perspectiva da interpretação dos contextos arqueológicos (como se tenta fazer aqui), a diversidade e complexidade do registro arqueológico proto-Je sugerem diversidade étnica e cultural bem maior e menos dicotômica - o que já se poderia deduzir da diversidade de designações (Gualachos, Guaianãs, etc) que estes grupos receberam desde os primeiros registros escritos disponíveis. Em outras palavras, não se trata de tentar uma correlação direta entre o registro arqueológico e o etnográfico na forma de possíveis conexões históricas, mas antes constatar que o que se documentou no final do século XIX e início do século XX é apenas uma parte de um leque de diversidade cultural e étnica muito mais amplo - e, na medida do possível, buscar construir interpretações que estabeleçam relações de caráter estrutural entre o registro arqueológico e o etnográfico.

Por fim, a natureza cerimonial do sítio é enfatizada ainda mais por sua inserção paisagística em local de amplo alcance visual e extraordinária grandiosidade cênica, dando, neste sentido, continuidade a um padrão de ocupação da região lagunar praticado pela sociedade sambaquieira que antecede a implantação deste sítio em pelo menos cinco mil anos - o que nos traz de volta à questão inicial deste artigo.

\section{Continuidade e mudança na paisagem do sul catarinense}

A associação entre sepultamentos, alguns deles dispostos à moda sambaquieira, artefatos usados e/ou depositados ritualmente, a grande quantidade de fauna a eles associada, indicando o intenso consumo de alimentos em um mesmo local e momento (ou momentos sucessivos, muito próximos) de comensalidade de natureza fúnebre, ritual e festiva, ecoa a longeva tradição funerária sambaquieira, onipresente na região, reforçando a percepção de continuidade (Klökler 2008, Gaspar et al 2008, Fish et al 2013). Os sambaquis ali presentes e sua relação com o cenário lagunar pontilhado de pontões rochosos não passaram despercebidos aos recémchegados que, a exemplo do que ocorre na ilha de Santa Catarina, mais ao norte (Fossari 2004), fizeram uso de lugares significativos da paisagem, como as ilhas costeiras, já milenarmente apropriadas por seus antecessores sambaquieiros. 
Velhas tradições e gente nova no pedaço: perspectivas longevas de arquitetura funerária na paisagem do litoral sul catarinense R. Museu Arq. Etn., 24: 109-136, 2014.

A cronologia revela que Galheta IV foi usado por um período consideravelmente longo, 500 a 600 anos pelo menos. Como o sítio é pequeno e com número de sepultamentos relativamente reduzido, depreende-se que era revisitado com certa regularidade e que apenas figuras destacadas (ou um subgrupo específico) foram ali sepultadas. Neste sentido, considerando-se a ausência de aldeias na região lagunar, fica-se com a impressão de que se trata de um local de peregrinação regular, ao qual se retorna periodicamente para honrar os mortos, para dispor de outro mais, para cerimônias iniciáticas. Tais usos se acoplam à obtenção dos abundantes recursos disponíveis no pontão rochoso e na laguna, seja exclusivamente por ocasião das cerimônias fúnebres, seja por conta do uso econômico mais intensivo do local. A grande quantidade de aves aquáticas no registro faunístico do sítio sugere que se trata de recursos circunstanciais, estacionais; parecem mais ligados às atividades que tem lugar no local do que a padrões habituais de dieta.

A perspectiva de continuidade com a tradição sambaquieira - e ao mesmo tempo, sua transformação - é reforçada pelas mudanças no regime deposicional que se percebe nos sambaquis da região a partir de $2000 \mathrm{AP}$ aproximadamente, já referidas no início deste artigo. Estas transformações sinalizam mudanças sociais e simbólicas significativas entre os sambaquieiros, talvez emuladas pelo contato, tímido em princípio, mas progressivamente mais intenso, com grupos de língua Je em expansão. São vários os "sambaquis sujos", ou "acampamentos conchíferos" (sítios rasos com "terra preta" e pouca concha, aqui designados "sambaquis tardios") que vão surgindo paulatinamente na laguna, com padrões funerários misturados (em decúbito frontal, fletidos, cremados), sugerindo contatos prolongados ao longo do segundo milênio que se intensificam em torno de 1600/1500 AP - apesar da ausência da diagnóstica cerâmica Taquara/Itararé.

Este horizonte de contatos e paulatina miscigenação entre jes e sambaquieiros, já bem reconhecido na costa central e setentrional de Santa Catarina (p.e. Schmitz 1996, Muller 2008, Bastos 2009), se estende também por toda a costa meridional, alcançando o litoral norte do Rio Grande do Sul (Schmitz 2006). Em Içara, cerca de $50 \mathrm{~km}$ ao sul da Galheta, foi escavado e descrito outro destes sítios póssambaquieiros com características funerárias mistas, típico deste período, onde a cerâmica também está ausente (Schmitz et al 1999; figura 4). Assim, em paralelo ao que ocorre ao longo de todo o litoral meridional do Brasil, Galheta IV parece se situar na fase final de um longo período de transformações sociais e econômicas na laguna, quando a presença das características culturais dos Je vai se tornando predominante, marcando o final da longa era sambaquieira.

Neste contexto, cabe considerar as diferenças entre os padrões funerários e deposicionais predominantes nos sambaquis da região e os apresentados neste estudo. Em Galheta IV as estruturas funerárias parecem configurar eventos discretos, não constituindo as áreas funerárias coletivas que tão significativamente definem o padrão funerário sambaquieiro, mesmo no período tardio desta ocupação, adentrando já o segundo milênio (Nishida 2007, Klökler 2008, Villagran et al 2010). Ao contrário: o espaçamento entre as estruturas funerárias, a dispersão dos vestígios e, ainda, o alinhamento discordante dos perfis provenientes de diferentes intervenções indicam que este sítio é constituído de diversos montículos mais ou menos isolados, um estilo de arquitetura funerária típica da Tradição Itararé e que na etnografia Je do Sul, como se viu acima, é bem característico dos grupos Kaingang do planalto meridional.

O perfil faunístico é, também, sobejamente distinto. Nos sambaquis restos ictiológicos e malacológicos predominam amplamente, criando estruturas estratigráficas complexas e mounds de grandes proporções. Neste sítio, onde as conchas são raras, predominam, além dos peixes, remanescentes ósseos de aves e mamíferos marinhos (principalmente botos, lobos marinhos e cormorões), configurando opções culturais muito diferentes no que se relaciona ao cardápio dos banquetes e oferendas fúnebres, remetendo a ênfases econômicas e simbólicas nitidamente diversas daquelas presentes nos sambaquis. Se a inserção paisagística comunga com a sambaquieira, este sítio evoca, no entanto, práticas 
econômicas e de comensalidade bem diferentes; considerando que se trata de banquetes fúnebres e que a escolha do "cardápio" não é casual, estas diferenças apontam também para visões de mundo, perspectivas simbólicas e míticas bastante distintas em relação ao mundo animal.

Diferentemente dos sambaquis, as conchas estão presentes discretamente no registro e são de espécies menos comuns e mais vistosas, o que sugere presença menos alimentar e mais simbólica - fortemente simbólica, se se considera que se trata de oferendas fúnebres, como parece ser o caso do conjunto de exemplares de Lucina junto ao sepultamento 5 . Neste sentido, talvez o uso ritual de conchas selecionadas como marcadores simbólicos pode ser visto como um traço de continuidade, apesar de não mais se usá-las em abundância, como material preferencial para a edificação dos mounds funerários.

Há, por fim, que se considerar a presença de sepultamentos cremados em Galheta IV, um traço cultural incomum nos sambaquis - exceto em seus níveis mais recentes e nos sambaquis tardios, datando do final do segundo milênio e, portanto, bastante próximos já do horizonte de ocupação deste sítio. A cremação, como se viu acima, é prática bastante comum entre os grupos Je do planalto e da encosta, documentados tanto arqueológica como etnograficamente. Neste sítio, aparece de forma consorciada à presença de sepultamentos compactados e fletidos, a maneira de sepultar mais comum entre os sambaquieiros - mas descrita também para os Kaingang por Mabilde (1988), entre outros. Esta associação é sugestiva, reforçando a percepção de que se está diante de um processo secular, prolongado, de aculturação e/ou miscigenação entre os Je e os sambaquieiros.

Apesar das diferenças cronológicas, estruturais, composicionais - e simbólicas - uma importante recorrência é notável: todos os sítios instalados na Ponta da Galheta compartilham da magnificência paisagística monumental do rochedo e, pelo menos o grande sambaqui da Galheta e este sítio tardio, Galheta IV, associam tal magnificência à presença de estruturas funerárias. Ao longo de todo o período transicional, marcado pelos sítios funerários de "terra preta" sem cerâmica (os "sambaquis tardios"), e também no que se refere a estes sítios (funerários ou não) tardios com cerâmica Taquara, os lugares de referência na paisagem que marcaram por milênios a ocupação sambaquieira (como a "ilha" de Santa Marta e a Ponta da Galheta), usados e reconhecidos recorrentemente por muitas e muitas gerações, permaneceram ativos, agenciando simbolicamente a vida na laguna antes e durante o processo gradual de transformação da milenar cultura sambaquieira em seu contato com os grupos de língua Je do Sul até o final desta era, marcado de maneira abrupta e definitiva pela irrupção súbita e maciça dos Guarani na laguna, por volta de 600 anos atrás (Milheira e DeBlasis 2011; ver fig. 4).

O sentido simbólico poderosamente evidente nesta recorrência suscita, de imediato, o reconhecimento de que, no processo gradual de interação cultural entre sambaquieiros e grupos de língua Je do Sul, estes últimos teriam herdado, no mínimo, uma percepção do território litorâneo fortemente marcada pela visão de mundo sambaquieira. A ausência de sítios habitacionais nas proximidades indica que o uso da ponta da Galheta - e outras, como Santa Marta e Costão do Ilhote - para atividades funerárias e cerimoniais implica em um amplo espectro territorial, envolvendo talvez peregrinações até o front costeiro. A possibilidade de que os pontões rochosos tenham tido também função econômica significativa, ligada à obtenção de recursos migratórios de inverno, como aventado mais acima, reforça ainda mais que estes locais, isolados do mainland continental, mas integrados ao ambiente lagunar, permaneceram significativos e referenciais ao longo de muitos milênios, desde a era sambaquieira até a instalação de um cenário onde passa a predominar a ordem social Je.

As reflexões acima dificilmente podem ser consideradas conclusivas. $\mathrm{O}$ fascinante tema do desaparecimento da milenar cultura sambaquieira - e o papel que os Je tiveram nesse processo - permanece ainda um tanto elusivo. Diferenças significativas, seja na maneira de sepultar ou na maneira de celebrar os mortos, apontam para preferências e estratégias econômicas dos grupos Je do Sul em relação aos recursos disponíveis, tanto na laguna como no mar, bastante diferen- 
tes daquelas dos sambaquieiros. Da mesma forma, indicam referenciais simbólicos distintos no que se refere às relações com o mundo animal, assim como em relação ao mundo dos mortos. Mas o estudo do sítio Galheta IV não deixa dúvidas que, apesar das grandes transformações ocorridas na região ao longo do segundo milênio antes do presente, a robusta tradição de ocupação do território através da percepção dos lugares significativos da paisagem e sua consagração ritual aos ancestrais não foi rompida.

\section{Agradecimentos}

Cabe, antes de tudo, agradecer aos numerosos estudantes que participaram ativamente das campanhas de escavação no sítio, em diferentes etapas entre 2004 e 2008. Sem eles este estudo não teria sido possível. $\mathrm{O}$ projeto Sambaquis e Paisagem, no âmbito do qual os estudos no sítio Galheta IV foram desenvolvidos, foi patrocinado principalmente pela FAPESP (11038-0). A pesquisa com os dados recebeu fundos do $\mathrm{CNPq}$. Agradecemos ainda a Tiago Attorre pelo processamento dos dados cronológicos e figuras, André Osório Rosa pela análise de uma amostra da fauna, Tatiane de Souza e Ketilin da Silva pela reconstituição e desenho das formas cerâmicas, Alexandro Demathé pela produção gráfica e aos bolsistas de Iniciação Científica do GRUPEP-UNISUL pela análise do material lítico e cerâmico (Rangel Recks, Luana Alves e Fabrícia Machado Fernandes).

DeBLASIS, P.; FARIAS, D. S.; KNEIP, A. Old traditions and new kids on the block: enduring patterns of funerary architecture in the southern Brazilian shores. R. Museu Arq. Etn., 24: 109-136, 2014.

Abstract: Located in a context that, both from a geographical as a historical perspective, situates it in between the long-lived sambaqui (shellmound) and the latecoming Southern Je cultures, Galheta IV is a funerary site bearing characteristics from both cultures, thus highlighting the fluidity of the contact between them. If, in one hand, it brings peculiar elements related to the Je, it also gets itself harmonically inserted in a landscape long dominated by the presence of the sambaquis.

Keywords: Southern Je, sambaquis, southern coast of Santa Catarina, coastal archaeology

\section{Referências bibliográficas}

Altman, D.G. e Bland, J.M. 1995. Absence of evidence is not evidence of absence. British Medical Journal 359: 57-61.

Araujo, A.G.M. 2001. Teoria e Método em Arqueologia Regional: um Estudo de Caso no Alto Paranapanema, Estado de São Paulo.
Tese de doutorado. São Paulo: Faculdade de Filosofia, Letras e Ciências Humanas, USP.

Assunção, D. 2010. Sambaquis da paleolaguna de Santa Marta: em busca do contexto regional no litoral sul de Santa Catarina. Dissertação de 
mestrado. São Paulo: Museu de Arqueologia e Etnologia, USP.

Baddeley, A. e Turner, R. 2005. Spatstat: an R package for analysing spatial point patterns. Journal of Statistical Software 12(6): 1-42.

Bailey, T. and Gatrell, A. 1995. Interactive spatial data analysis. Harlow: Pearson Education.

Bastos, M. 2009. Mobilidade humana na pré-história do litoral brasileiro: análise de isótopos estáveis de estrôncio no sambaqui Forte Marechal Luz. Dissertação de mestrado. Rio de Janeiro: Escola Nacional de Saúde Pública, FIOCRUZ.

Beber, M.V. 2005. O sistema do assentamento dos grupos ceramistas do planalto sul-brasileiro: o caso da Tradição Taquara/Itararé. Documentos 10: 5-125.

Becker, I.I.B. 1995. O indio Kaingang no Rio Grande do Sul. São Leopoldo: Ed. UNISINOS.

Belem, F. 2012. Do seixo ao zoólito. A indústria lítica dos sambaquis do sul catarinense: aspectos formais, tecnológicos e funcionais. Dissertação de mestrado, São Paulo: Museu de Arqueologia e Etnologia, USP.

Bianchini, G.F.; Gaspar, M.D.; DeBlasis P. e Scheel-Ybert R. 2011. Processos de formação do sambaqui Jabuticabeira II: interpretações através da análise estratigráfica de vestígios vegetais carbonizados. Revista do Museu de Arqueologia e Etnologia 21: 51-69.

Bivand, R. 2007. Using the R-GRASS interface. OS Geo Journal 1: 1-4.

Chmyz, I. e Sauner, Z.C. 1971. Nota prévia sobre as pesquisas arqueológicas no vale do rio Piquiri. Dédalo 13: 7-36.

Copé, S.M. 2007. El uso de la arquitectura como artefacto en el estudio de paisajes arqueológicos del altiplano sur brazilieño. Revista de Arquelogía (Universidad de Mar del Plata) 2: 15-34.

Copé, S.M. e Saldanha, J.D. 2002. Em busca de um sistema de assentamento para o Planalto Sul-Rio-Grandense: Escavações no sítio RS-AN-03, Bom Jesus, RS. Pesquisas Antropologia 58: 107-120. Instituto Anchietano de Pesquisas, São Leopoldo.

Corteletti, R. 2012. Projeto Arqueológico Alto Canoas - PARACA. Um estudo da presença Je no Planalto Catarinense. Tese de Doutoramento, Museu de Arqueologia e Etnologia, USP.

DeBlasis, P. 2000. Resgate arqueológico no traçado do Gasoduto Bolivia Brasil (GASBOL) no Estado de São Paulo: trechos IX e X (de Paulinia à fonteira com o Paraná). Relatório final para a Petrobrás.

DeBlasis, P; Suzanne, F.; Gaspar, M.D. e Fish, P. 1998. Some references for the discussion of complexity among the sambaqui moundbuilders from the southern shores of Brasil. Revista de Arqueologia Americana 15: 75-105, Mexico, Instituto Panamericano de Geografia e Historia.

DeBlasis, P.; Kneip, A.; Scheel-Ybert, R.; Giannini P. e Gaspar, M.D. 2007. Sambaquis e paisagem. Arqueologia Suramericana 3: 29-61.

DeBlasis, P. e Gaspar, M.D. 2009. Os sambaquis do sul catarinense: retrospectiva e perspectivas de dez anos de pesquisas. In Morales, W.F. (Org.) Arqueologia Hoje. Especiaria (Cadernos de Ciências Humanas) 11/12 (20/21): 83-125. Ilhéus, Editora da UESC.

DeMasi, M.A.N. 2006. Xokleng 2860 a.C. As terras altas do Sul do Brasil. Tubarão: Editora UNISUL.

Diggle, P. J. 2003. Spatial analysis of spatial point patterns. London: Arnold. 
Farias, D.S. 2005. Distribuição e padrão de assentamento - propostas para sítios da Tradição Umbu na encosta de Santa Catarina. Tese de doutorado. Porto Alegre: PUCRS.

Farias, D.S. 2010. Pesquisa arqueológica na Encosta de Santa Catarina - O Projeto AMA. Anais da SAB-Sul, Jaguarão, RS.

Farias, D.S. e DeBlasis, P. 2007. Notas prévias sobre a escavação do sítio Galheta IV. In: Cappelletti, A.M.; Farias, D.S.E.; Arnt, F.V. e Beber, M.V. (orgs.) Anais do V Encontro do Núcleo Regional da SABsul, CD-rom.

Farias, D.S. e Kneip, A. 2010. Panorama Arqueológico de Santa Catarina. Palhoça: Ed. UNISUL.

Fernandes, F.M., Farias, D.S.E. e DeBlasis, P. 2011. Análise da indústria lítica do sítio Galheta IV: investigando a tecnotipologia lítica Je no litoral sul de Santa Catarina. In Barcelos, Artur HF, Claudia I. Parellada e Juliano B. Campos (orgs.) Arqueologia no sul do Brasil, p. 305-329. Criciuma, SAB-Sul/UNESC.

Figuti, L. 1993. O homem pré-histórico, o molusco e o sambaqui: considerações sobre a subsistência dos povos sambaquieiros. Revista do Museu de Arqueologia e Etnologia 3: 67-80, Museu de Arqueologia e Etnologia, USP.

Fish, S.K.; DeBlasis, P.; Gaspar, M.D. e Fish, P.R. 2000. Eventos incrementais na construção de sambaquis, litoral sul do Estado de Santa Catarina. Revista do Museu de Arqueologia e Etnologia 10: 69-87.

Fish, P.R.; Fish, S.K.; DeBlasis, P. e Gaspar, M.D. 2013. Monumental Shell Mounds as Persistent Places in Southern Coastal Brazil. In Thompson, V.D.; Waggoner Jr., J.C. (Eds.) The Archaeology and Historical Ecology of Small Scale Economies: 120-140. Gainesville: Univ. Press of Florida.

Fossari, T.D. 2004. A população pré-colonial Je na paisagem da Ilha de Santa Catarina. Tese de doutorado. Florianópolis: UFSC.
Gakran, N. 2005. Aspectos morfossintáticos da língua Laklãño (Xokleng). Dissertação de mestrado. Campinas: UNICAMP.

Gaspar, M.D. 2000. Sambaquis. Arqueologia do litoral. Rio de Janeiro, Jorge Zahar Editora.

Gaspar, M.D.; DeBlasis, P.; Fish, S.K. e Fish, P. 2008. Sambaqui (Shell Mound) Societies of Coastal Brazil. In: Silverman, H. e Isbell, W.H. (Eds.) Handbook of South American Archaeology, p. 319-335. Springer.

Giannini, P.C.F.; Villagrán, X.S.; Fornari, M.; Nascimento Junior, D.R.; Menezes, P.M.L.; Tanaka, A.P.B.; Assunção, D.C.; DeBlasis, P. e Amaral, P.G.C. 2010. Interações entre evolução sedimentar e ocupação humana pré-histórica na costa centro-sul de Santa Catarina, Brasil. Boletim do Museu Paraense Emilio Goeldi (Ciências Humanas) 5(1): 105 128, Belém.

GRASS Development Team. 2010. Geographic Resources Analysis Support System (GRASS GIS) Software. USA. http://grass.osgeo.org.

Henry, J. 1964. Jungle People: A Kaingáng Tribe of the Highlands of Brazil. New York: Vintage Books.

Hurt, W.R. 1974. The interrelationship between the natural environment and four sambaquis, coast of Santa Catarina, Brasil. Occasional Papers and Monographs 1, Bloomington, Indiana University Museum.

Iriarte, J.; Gillam, J.C.; Marozzi, O. 2008. Monumental burials and memorial feasting: an example from the southern Brazilian highlands. Antiquity 82: 947-961.

Iriarte, J.; Copé, S.M.; Fradley, M.; Lockhart, J.J. e Gillam, J.C. 2012. Sacred landscapes of the southern Brazilian highlands: understanding southern proto-Je mound and enclosure complexes. Journal Anthrop. Archaeol. http://dx.doi.org/10.1016/ j.jaa.2012.10.003 
Jones, M. 2007. Feast: why humans share food. Oxford University Press.

Klökler, D.M. 2008. Food for body and soul: mortuary ritual in shellmounds (Laguna, Brazil). Tese de doutorado. Tucson: Department of Anthropology, University of Arizona.

Kneip, A. 2004. O povo da lagoa: uso do SIG para modelamento e simulação na área arqueológica do Camacho. Tese de doutorado. São Paulo: Museu de Arqueologia e Etnologia. USP.

Lavina, R. 1994. Os Xokleng de Santa Catarina: uma etnohistória e sugestões para os arqueólogos. Dissertação de mestrado. São Leopoldo: Instituto Anchietano de Pesquisas/UNISINOS.

Mabilde, A.P.T. 1988. Apontamentos sobre indígenas selvagens da nação coroados que habitavam os sertões do Rio Grande do Sul. Documentos 2, São Leopoldo, Instituto Anchietano de Pesquisas.

McCormac F.G.; Hogg, A.G.; Blackwell, P.G.; Buck C.E.; Higham T.F.G.; Reimer P.J. 2004. SHCal04 Southern Hemisphere calibration, 0-11.0 cal kyr BP. Radiocarbon 46(3): 1087-1092.

Milheira, R.G. e DeBlasis, P. 2011. O território Guarani no litoral sul catarinense: ocupação e abandono no limiar do período colonial. Revista de Arqueologia Americana 29:147-182.

Müller, L. 2008. Sobre indios e ossos: estudo de três sitios de estruturas anelares construidos para enterramentos por populações que habitavam o vale do rio Pelotas no periodo pré-contato. Dissertação de mestrado. Porto Alegre: PPGH-PUCRS.

Neteler, M. e Mitasova, H. 2004. Open source GIS: a GRASS GIS approach. Boston, Kluwer.

Nishida, P. 2007. A coisa ficou preta: estudo do processo de formação da terra preta do sítio arqueológico Jabuticabeira II. Tese de doutorado. São Paulo: Museu de Arqueologia e Etnologia, USP.

Noelli, F.S. 2000. Repensando os rótulos e a história dos Jê no sul do Brasil a partir de uma interpretação interdisciplinar. In Mota, L.T.; Noelli, F.S. e Tommasino K. (Orgs) Uri e Wãxi: estudos interdisciplinares dos Kaingang. Londrina: Editora UEL, 9-58.

Peixoto, S.A. 2008. Pequenos aos montes: uma análise dos processos de formação dos sambaquis de pequeno porte do litoral sul de Santa Catarina. Dissertação de mestrado. Rio de Janeiro: Museu Nacional, UFRJ.

Reimer, P.J.; Baillie, M.G.L.; Bard, E.; Bayliss, A.; Beck, J.W.; Blackwell, P.G.; Bronk, R.C.; Buck, C.E.; Burr, G.S.; Edwards, R.L.; Friedrich, M.; Grootes, P.M.; Guilderson, T.P.; Hajdas, I.; Heaton, T.J.; Hogg, A.G.; Hughen, K.A.; Kaiser, K.F.; Kromer, B; McCormac, F. G.; Manning, S.W.; Reimer, R.W.; Richards, D.A.; Southon, J.R.; Talamo, S.; Turney, C.S.M.; van der Plicht, J.; Weyhenmeyer, C.E. 2009. IntCal09 and Marine09 Radiocarbon Age Calibration Curves, 0-50,000 Years cal BP. Radiocarbon 51(4): 1111-1150.

Ribeiro, L.B. 2002. Limpando ossos e expulsando mortos: estudo comparativo de rituais funerários em culturas indígenas brasileiras através de uma revisão bibliográfica. Dissertação de mestrado. Florianópolis: Programa de Pós Graduação em Antropologia Social, UFSC, .

Ripley, B.D. 1977. Modelling Spatial Patterns. Journal of the Royal Statistical Society series B (Methodological) 39(2): 172-212.

Rohr, J.A. 1969. Os sítios arqueológicos do município sul-catarinense de Jaguaruna. Pesquisas (Antropologia) 22: 1-39.

Rohr, J.A. 1984. Sítios arqueológicos de Santa Catarina. Anais do Museu de Antropologia 17: 70-167. 
Saldanha, J.D.M. 2005. Paisagem, lugares e cultura material. Dissertação de mestrado. Porto Alegre: Departamento de Historia, PUCRS.

Santos, S.C. 1973. Índios e brancos no sul do Brasil - a dramática experiência dos Xokleng. Florianópolis: Edeme.

Scheel-Ybert, R.; Eggers, S.; Wesolowski, V.; Petronilho, C.C.; Boyadjian, C.H.; Gaspar, M.D.; Barbosa-Guimarães, M.; Tenório, M.C. e DeBlasis, P. 2009. Subsistence and lifeway of coastal Brazilian moundbuilders. In: Aylen Capparelli, Alexandre Chevalier e Raquel Piqué (coords.) La alimentación en la América precolombina y colonial: una aproximación interdisciplinaria. Treballs D'etnoarque-ologia 7: 37-54. Madrid, Consejo Superior de Investigaciones Científicas.

Schmitz, P.I. 1988. As tradições ceramistas do Planalto sul-brasileiro. Documentos 2, São Leopoldo, Instituto Anchietano de Pesquisas.

Schmitz, P.I. 1996. Visão de conjunto dos sítios da Tapera, Armação do Sul, Laranjeiras I e II, Pântano do Sul e Cabeçudas. Pesquisas 53: 183-190.

Schmitz, P.I. (coord.). 2006. A ocupação pré -histórica do litoral meridional do Brasil. Pesquisas (Antropologia) 63: 355-364.

Schmitz, P.I.; Rosa, A.O.; Izidro, J.M.; Haubert, F.; Krever, M.L.B.; Bitencourt, A.L.V.; Rogge, J.H. e Beber,M.V. 1999. Içara: um jazigo mortuário no litoral de Santa Catarina. Pesquisas (Antropologia) 55.

Schmitz, P.I., Arnt, F.V.; Beber, M.V.; Rosa, A.O. e Farias, D.S. 2010. Casas subterrâneas no planalto de Santa Catarina: São
José do Cerrito. Pesquisas Antropologia 68: 7-78.

Silva, S.B. 2001. Etnografia dos grafismos kaingang: um modelo para a compreensão das sociedades Proto-Jê Meridionais. Tese de doutorado. São Paulo: Programa de Pós Graduação em Antropologia Social, USP.

Souza, J.G. e Copé, S.M. 2011. Novas perspectivas sobre a arquitetura ritual do planalto meridional brasileiro: pesquisas recentes em Pinhal da Serra, RS. Revista de Arquelogia (SAB) 23: 104-117.

Stuiver, M., and Reimer, P.J. 1993. Extended $14 \mathrm{C}$ data base and revised CALIB $3.014 \mathrm{C}$ age calibration program. Radiocarbon 35(1): 215-230.

Veiga, J. 2000. A retomada da festa do Kikikoi no P.I. Xapecó e a relação desse ritual com os mitos Kaingang. In: Motta, L.T. (ed.) Uri e Wãxi: Estudos Interdisciplinares dos Kaingang. Londrina, EUL, pp. 261-292.

Veiga, J. 2006. Aspectos Fundamentais da Cultura Kaingang. Campinas: Editora Curt Nimuendajú.

Villagrán, X.S. 2012. Micromorfologia de sítios concheiros da América do Sul: arqueoestratigrafia e processos de formação de sambaquis (Santa Catarina, Brasil) e concheros (Terra do Fogo, Argentina). Tese de Doutorado. S Instituto de Geociências, USP.

Villagrán, X.S., Klokler, D.; Nishida, P.; Gaspar, M. D.; DeBlasis, P. 2010. Lecturas estratigráficas: arquitetura funeraria y depositación de resíduos em el sambaqui Jabuticabeira II. Latin American Antiquity 21(2): 195-216. 